\title{
Monetary Policy Switch, the Taylor curve, and the Great Moderation*
}

\author{
Efrem Castelnuovo \\ University of Padua
}

First version: January 2006

\begin{abstract}
This paper employs a standard new Keynesian model to compute the inflation/output volatility frontier, i.e. the "Taylor curve". The computation is performed both under equilibrium uniqueness and under indeterminacy. While under uniqueness the Taylor curve looks like expected - i.e. a monotonically decreasing curve in the $\left(\sigma_{x}, \sigma_{\pi}\right)$ diagram -, under indeterminacy a new result arises. We find that the tighter is the monetary policy, the higher is the inflation/output gap volatility. This is due to impact of systematic monetary policy on inflation and output persistence. In fact, under indeterminacy a more aggressive monetary policy causes an increase in inflation persistence, and augments its volatility. The effects on output tend to be of opposite sign. This finding is robust to different parameterization of the DSGE new-Keynesian monetary model employed. This result i) offers support the move from "passive" to "active" monetary policy as one of the possible rationales for the Great Moderation, ii) underlines the need of a deeper understanding of the link between systematic monetary policy and macroeconomic persistence, and iii) warns against sub-samples pooling when performing macroeconometric analysis.
\end{abstract}

JEL classification: E30, E52.

Keywords: Taylor principle, Taylor curve, new Keynesian model, indeterminacy, persistence.

*Address for correspondence: Efrem Castelnuovo, Department of Economics, University of Padua, Via del Santo 33, I-35123 Padova (PD). E-mail: efrem.castelnuovo@unipd.it. 


\section{Introduction}

Most monetary authorities aim at stabilizing inflation and the business cycle. The relative importance attributed to the former objective with respect to the latter drives the choices that monetary policymakers undertake to tackle the shocks that drive the variables of interest off-targets. Taylor (1979) offered a graphical syntesis of the impact of such preferences on the targeted variables: The downward sloping curve collecting the different pairs of inflation and output volatilities - computed with a macroeconomic model in which the central bank varies its aggressivity against inflation fluctuations - has been labeled as "Taylor curve". ${ }^{1}$ The Taylor curve shows that monetary authorities face a trade-off between inflation and business cycle stabilization: To move towards a scenario featured by a lower inflation volatility, a Society must let the real side of the economy fluctuate more (all else being equal).

This conclusion is typically reached in studies concentrating on equilibrium uniqueness. However, it is well known that multiple equilibria may arise in an economy featured by the presence of rational agents and in which monetary policy is approximated by a simple rule. A case of particular interest is that concerning the workhorse new Keynesian model "closed" with a policy rule a la Taylor (1993). In such a context, it is possible to define a threshold measure for the reactiveness monetary authorities have to display for pinning down private sector's expectations and, consequently, uniquely determine the equilibrium values of inflation and the output gap (Clarida et al, 2000; Woodford, 2003). Such a threshold is the basis for the so-called "Taylor principle": Monetary authorities must raise the nominal interest rate more than one-to-one in reaction to an upward shift in inflation in order to rule out self-fulfilling expectations fluctuations and stabilize inflation.

The goal of this paper is to understand how the Taylor curve looks like when the Taylor principle is violated and monetary policy is therefore classifiable as "passive". Does a volatility trade-off still exist under multiple equilibria? Does it still work as under determinacy? Although the relevance of these questions seem to be clear, to our knowledge no study in the literature has attempted to answer them so far. We try to close this gap by employing a standard DSGE model in which a Taylor rule formalizes the behavior of the monetary authorities. We investigate the case in which the Taylor principle is not met - i.e. passive monetary policy -, and we contrast it with a more standard analysis in which inflation expectations are well anchored by an aggressive policy conduct. Following Lubik and Schorfheide (2003,2004), we deal with indeterminacy by imposing additional constraints on the dynamics of the system, so selecting one solution out of all the multiple equilibria consistent with rational expectations.

\footnotetext{
${ }^{1}$ Taylor (1979) computed the Taylor curve by considering the unique optimal monetary policy under rational expectation to be implemented in a set up in which an inflation targeter minimizes a loss function subject to the structure of the economy. By contrast, this paper investigates the inflation/output volatility issue in a set up in which monetary authorities follow a simple rule, and sunspot fluctuations may arise when a weak policy conduct is implemented.
} 
Another goal of this study is that of understanding if the joint reduction in inflation and the business cycle volatilities may be attributed to such a switch in the systematic monetary policy. Indeed, as far as the U.S. case is concerned, several researchers - e.g. Clarida et al (2000), Boivin and Giannoni (2003), Lubik and Schorfheide (2004), and Cogley and Sargent (2005) - argue that monetary policy did not react aggressively enough to the inflationary shocks hitting the American economy during the pre-' 79 period. ${ }^{2}$ Then, it is not to be excluded that this violation of the Taylor principle allowed for sunspot fluctuations of inflation and output. But the standard Taylor curve predicts that to lower the volatility of the former a Society must accept larger fluctuations of the real GDP. Does the move from a passive to an active monetary policy trigger a reduction of both volatilities? A positive answer to this question would offer an alternative explanation to the empirical evidence pointing towards a paramount decrease in the volatilities of inflation and the output gap in the last two decades, labeled by Bernanke (2004) as the "great moderation".

We achieve the following results. First, under indeterminacy the tighter the monetary policy, the higher is the inflation/output gap volatility. This is due to impact of systematic monetary policy on inflation and output persistence. In fact, under indeterminacy the tigher the policy, the higher the persistence of inflation, the larger its volatility. The effects on output seem to be of opposite sign. The move from passive to active monetary policy causes a drop in macroeconomic persistence and volatility. Moreover, some policies may be Paretosuperior with respect to others. Our findings tend to support i) the move from "passive" to "active" monetary policy as one of the possible rationales for the Great Moderation, ii) underline the need of a deeper understanding of the link between systematic monetary policy and macroeconomic persistence, and iii) warn against sub-samples pooling when performing macroeconometric analysis. This result is robust to several perturbations of the benchmark model we employ.

The paper is structured as follows. Section 2 presents the model, and explains how we pick up a single equilibrium under indeterminacy. Section 3 explains the algorithm we implement for drawing the Taylor curve, and discusses the benchmark parameterization of the model. Section 4 presents and discusses the results. Section 5 concludes, and References follow. A Technical Appendix is then provided.

\section{The economic framework}

In stabilizing inflation and the output gap, policymakers face the inflation/output volatility trade-off. Taylor (1979) - and several subsequent contributions, see e.g. the papers collected in Taylor (1999) - concentrate on the unique equilibrium implied by (each of the) optimal monetary policy (ies) computed under rational expectation in a set up in which an inflation

\footnotetext{
${ }^{2}$ It must be acknowledged that this view is not uncontended, see e.g. Sims and Zha (2005).
} 
targeter minimizes a loss function subject to the structure of the economy. Our analysis relaxes the assumption of equilibrium uniqueness, and employes a simple policy rule to represent the policymakers behavior both under determinacy and under weak monetary policy.

To construct the Taylor curves presented in the following Section we employ the following standard DSGE model: ${ }^{3}$

$$
\begin{gathered}
\pi_{t}=\frac{\beta}{1+w \beta} E_{t} \pi_{t+1}+\frac{w}{1+w \beta} \pi_{t-1}+\kappa x_{t}+\varepsilon_{t}^{\pi} \\
x_{t}=\frac{1}{1+b} E_{t} x_{t+1}+\frac{b}{1+b} x_{t-1}-\frac{1-b}{\sigma(1+b)}\left(R_{t}-E_{t} \pi_{t+1}\right)+\varepsilon_{t}^{x} \\
R_{t}=\rho_{\pi} \pi_{t}+\rho_{y} x_{t}+\varepsilon_{t}^{M P}
\end{gathered}
$$

where $x$ stands for real output, $\pi$ represents the growth rate of the relevant aggregate price index, $R$ the short term nominal interest rate, and $\varepsilon_{t}^{\pi}, \varepsilon_{t}^{x}$, and $\varepsilon_{t}^{M P}$ are zero-mean i.i.d. stochastic structural shocks having - respectively - variance $\sigma_{\varepsilon^{\pi}}^{2}, \sigma_{\varepsilon^{x}}^{2}$, and $\sigma_{\varepsilon^{M P}}^{2}$.

Eq. (1) is the Euler equation maximizing the profits of monopolistically competitive firms whose discount factor is identified by the parameter $\beta$. We assume a staggered price setting regulated by a Calvo-type mechanism, i.e. there is a probability $\theta$ for a firm of not reoptimizing its price in each period. Among the firms who cannot reoptimize, there is a fraction $w$ that automatically adjust the price level according to a mechanical rule, i.e. $P_{j, t}=\pi_{t-1} P_{j, t-1}$, where $j$ is the firm-index. ${ }^{4}$ The parameter expressing the link between demand fluctuations and inflation reactions is a convolution of the already presented structural parameters, i.e. $\kappa \equiv \frac{(\sigma+\eta)(1-\theta)(1-\theta \beta)}{(1+w \beta) \theta}$. Finally, we admit the presence of a cost-push shock $\varepsilon_{t}^{\pi}$.

Eq. (2) is a log-linearized IS curve stemming from the household's intertemporal problem in which consumption and bond holdings are the control variables. Contemporaneous output is caused both by expectations on future realizations of the business cycle and by its past values. The ex-ante real interest rate exerts a direct, contemporaneous impact on the cycle. The coefficient $b$ regulates the importance of (external) habits in the household's utility function, and concurs to "weight" the just mentioned elements. ${ }^{5}$ The shock $\varepsilon_{t}^{x}$ may be interpreted as a demand shock, or a shock to household's preferences.

\footnotetext{
${ }^{3}$ The variables of the model are expressed in percentage deviation with respect to their steady state values.

${ }^{4}$ Notice that there exists a difference between the adjustment mechanims embedded in this model and the rule-of-thumb behavior a la Galí et al (2001). In this model firms who cannot reoptimize in a given period adopt an automatic adjustment a al Christiano et al (2005). By contrast, the rule-of-thumb behavior a la Galí et al (2001) applies to firms who are able to reoptimize.

${ }^{5}$ In this set up, the preferences of the representative consumer are identified by the following utility function: $u\left(C_{t}, X\right)=\frac{\left(C_{t}-H_{t}\right)^{1-\sigma}}{1-\sigma}+f(X)$, where $H_{t}=b C_{t-1}$ and $X$ is the bunch of remaining arguments affecting consumer's utility.
} 
Eq. (3) is an interest rate rule according to which the central bank adjusts the policy rate in response to fluctuations in inflation and the output gap. We interprest the random variable $\varepsilon_{t}^{x}$ as the monetary policy shock.

It is well known that the linear rational expectations model (1)-(3) can be associated to a unique solution as long as the Taylor principle is satisfied, i.e. the condition $\rho_{\pi}>1-\frac{(1-\beta)}{\kappa} \rho_{y}$ is met (Clarida et al, 2000; Woodford, 2003). By contrast, if $\rho_{\pi} \leq 1-\frac{(1-\beta)}{\kappa} \rho_{y}$, monetary authorities are unable to uniquely pin down private sector's expectations, and there is room for self-fulfilling fluctuations triggered by sunspot shocks hitting the economy. ${ }^{6}$ Formally, in this model the equilibrium/equilibria are computed as follows:

$$
s_{t}=\Gamma_{1}^{*} s_{t-1}+\left[\Psi^{*}-\Pi^{*} V_{.1} D_{11}^{-1} U_{.1}^{\prime} Q_{2 .} \Psi+\Pi^{*} V_{.2} \widetilde{M}\right] \varepsilon_{t}+\Pi^{*} V_{.2} \zeta_{t}
$$

where $s_{t}=\left[x_{t}, \pi_{t}, R_{t}, E_{t} x_{t+1}, E_{t} \pi_{t+1}\right]^{\prime}$ collects the $n$ variables of the system, $\varepsilon_{t}=\left[\varepsilon_{t}^{M P}, \varepsilon_{t}^{\pi}, \varepsilon_{t}^{x}\right]$ is the vector of $l$ fundamental shocks, $\zeta_{t}$ is the sunspot shock hitting the economy. As shown by Lubik and Schorfheide (2003,2004), under uniqueness $V_{.2}=0_{[l x 1]}$, then the last two terms of (4) drop out and the equilibrium values of the variables belonging to the vector $s_{t}$ are completely identified by the structure of the economy. By contrast, under indeterminacy the i.i.d. zero mean sunspot shock $\zeta_{t}$ - whose variance is $\sigma_{\zeta}^{2}$ - influences households' expectations and, consequently, the equilibrium values of inflation, the output gap, and the policy rate. Notice that in this scenario the matrix $\widetilde{M}$ may affect the transmission mechanism linking the structural shocks to the variables of the system. Lubik and Schorfheide (2004) propose to compute such matrix by requiring that the on-impact reaction of the endogenous variables $s_{t}$ to the shocks $\varepsilon_{t}$ be as close as possible to the one on the frontier dividing the parameter space into determinacy and indeterminacy, a scenario labeled as "continuity". ${ }^{7}$ As an alternative, Lubik and Schorfheide (2003) consider the possibility of setting $\widetilde{M}=0_{[1 x l]}$, a scenario labeled as "orthogonality". In drawing the Taylor curve under indeterminacy we will alternatively employ these two identification schemes.

\footnotetext{
${ }^{6}$ To understand why, suppose that inflation expectations suddenly raise merely due to a sunspot shock. According to the Phillips curve (1), inflation should raise, but the policy rate reacts as well given the prescriptions of the Taylor rule (3). However, since the Taylor principle is not met, the real expected interest rate eventually decreases and boosts the real side of the economy. Eventually, inflation is pushed up by the demand channel. Hence, in equilibrium inflation is off-target even if no structural shock has hit the economy.

${ }^{7}$ Following Lubik and Schorfheide $(2004), \widetilde{M}=\left[B_{2}^{\prime}(\theta) B_{2}(\theta)\right]^{-1} B_{2}^{\prime}(\theta)\left[B_{1}(\widetilde{\theta})-B_{1}(\theta)\right]$, where $\theta=$ $\left[\rho_{\pi}, \ldots, \sigma_{\varepsilon^{M P}}^{2}\right]$ is the vector of the parameters of the model, $\widetilde{\theta}=\left[\widetilde{\rho_{\pi}}, \ldots, \sigma_{\varepsilon^{M P}}^{2}\right]$ is a "manipulated" vector whose only different element with respect to $\theta$ is $\widetilde{\rho_{\pi}}=1-\frac{(1-\beta)}{\kappa} \rho_{x}$ (a value positioning the economy on the indeterminacy frontier), $\frac{\partial s_{t}}{\partial \varepsilon_{t}^{\prime}}(\theta)=B_{1}(\theta)+B_{2}(\theta)=\Psi^{*}-\Pi^{*} V_{.1} D_{11}^{-1} U_{.1}^{\prime} Q_{2} . \Psi+\Pi^{*} V_{.2} \widetilde{M}$, and $\frac{\partial s_{t}}{\partial \varepsilon_{t}^{\prime}}(\widetilde{\theta})=B_{1}(\widetilde{\theta})$. See the Technical Appendix for more details.
} 


\section{Drawing the Taylor Curve}

To draw the Taylor curve, we implement the following algorithm. First, we fix the values of $\rho_{\pi}$ and $\rho_{x}$. Then, given the calibration of the structure of the model, we compute the rational expectation solution. Notice that, in case of $\rho_{\pi} \leq 1-\frac{(1-\beta)}{\kappa} \rho_{x}$, we select one of the multiple solutions consistent with rational expectations by choosing either "continuity" or "orthogonality" (as described in the previous Section). At that point, the unconditional volatilities of inflation and the output gap are computed by constructing samples of 110,000 simulated observations (whose initial 10,000 observations are then discarded as burn-in observations). We then store the results, perturb the value of $\rho_{\pi}$, and repeat all the steps. ${ }^{8}$ Finally, we collect all the pairs of inflation-output volatilities conditional to a given parameterization of the structural model (1)-(2) and a given value of $\rho_{x}$.

We now turn to our benchmark calibration of the model (1)-(3). Regarding the Phillips curve, we fix the discount factor $\beta=0.99$, as commonly done in the literature in case of models for quarterly frequencies. The degree of price indexation $w$ is set to be equal to 0.90, as in Rabanal (2006) and close to the "full indexation" hypothesis by Christiano et al (2005). We select a Calvo-parameter $\theta$ equal to 0.80 as in Rabanal (2006) and Christiano et al (2005), and slighly higher than the one proposed by Galí et al (2003). As far as households' risk aversion and labor elasticities are concerned, we select $\sigma=1$ and $\eta=1$, fairly standard values in the literature. ${ }^{9}$ Moving to the IS curve, we impose a degree of habit formation $b=.65$ (in line with Christiano et al, 2005; Rabanal, 2005; Dennis, 2005), which implies an intertemporal elasticity of substitution equal to 0.2121, very similar to the set of estimates proposed by Fuhrer and Rudebusch (2004). The Taylor rule is featured by $\rho_{\pi}$ ranging from 0 to 2 , while $\rho_{x}$ assumes a value belonging to the set $\{0,0.25,0.5,1\}$. Finally, to calibrate our volatilities we refer to the study by Lubik and Schorfheide (2004) in which a model similar to (1)-(3) is estimated under passive monetary policy. In particular, we set $\sigma_{\varepsilon^{\pi}}^{2}=1.16, \sigma_{\varepsilon^{x}}^{2}=0.21, \sigma_{\varepsilon^{M P}}^{2}=0.24$, and the volatility of the sunspot $\sigma_{\zeta}^{2}=0.24$. We now turn to the presentation and comment of our results.

\section{Results}

Figure 1 displays the Taylor curves computed under uniqueness in the benchmark scenario conditional of four different values of the parameter $\rho_{x}$. As expected, the Taylor curve depicts a monotonically decreasing function in the $\left(\sigma_{x}, \sigma_{\pi}\right)$ diagram, i.e. the higher is the systematic reaction of the nominal interest rate in eq. (3), the lower the inflation/output gap volatility

\footnotetext{
${ }^{8}$ We vary $\rho_{\pi}$ in the sub-domain $[0,2]$, and adopt a step-length equal to 0.1 .

${ }^{9}$ These values imply an inverse of the sacrifice ratio $\kappa=0.0352$, lower than other values present in the literature, e.g. 0.10 as in Ireland (2004). However, notice that the sacrifice ratio is inversely related to the degree or relative risk aversion $\sigma$, which will be augmented by a factor of 5 in the robustness check.
} 
ratio (all else being equal). This is "conventional wisdom" in the literature [see for instance some of the contributions in Taylor (1999)]..$^{10}$

\section{[insert Figure 1 about here]}

The picture dramatically changes when the Taylor principle is not met (Figure 2). ${ }^{11}$ In fact, the world under indeterminacy turns upside down. Under indeterminacy, the higher the reaction of the policy rate to inflation fluctuations, the higher the inflation/output volatility ratio! Interestingly, this finding holds both under orthogonality and under continuity. Moreover, by looking at the values of the volatilities plotted in Figure 2, we can notice that this finding becomes more clear the higher is the reaction of the policy rate to the oscillations of the output gap. This is due to the much higher volatility of inflation positively triggered by $\rho_{x}$, that "stretches" the Taylor curve and renders even more clear the surprising behavior of the curve. Moreover, we can also observe some "zig-zags" that are typically not present when monetary policy is active. In other words, the curves are not necessarily monotonic. This is a strong result, because it implies that some policies are Pareto-superior with respect to others. For instance, the continuity case displayed in the north-east panel in Figure 3 witness that the policy identified by $\left(\rho_{\pi}=0.2, \rho_{x}=0.25\right)$ - which implies the unconditional volatilities $\left(\sigma_{x}=4.74, \sigma_{\pi}=3.41\right)$ - is Pareto superior with respect to the policy $\left(\rho_{\pi}=0.3, \rho_{x}=0.25\right)$ that delivers $\left(\sigma_{x}=4.80, \sigma_{\pi}=3.73\right)$.

\section{[insert Figure 2 about here]}

\subsection{Monetary Policy, Macroeconomic Persistence, and Volatility}

The results presented so far point towards a switch in the relationship between monetary policy tightness and inflation-output volatility when moving from passive to active monetary policy. Under passive monetary policy, such relationship is direct, while under active monetary policy is inverse. To better understand this link, it is interesting to analyze the link between monetary policy and persistence, and the link between persistence and volatility. Concentrate on the latter, and consider the following reduced form autoregressive process:

$$
z_{t}=\phi_{1} z_{t-1}+\phi_{2} z_{t-2}+\ldots+\phi_{n} z_{t-n}+\xi_{t}^{z}
$$

\footnotetext{
${ }^{10} \mathrm{~A}$ closed form solution for the volatility ratio can be easily computed for a version of the model displaying no endogenous persistence, i.e. $w=b=0$. In fact, given the white noise nature of the structural shocks, $E_{t} \pi_{t+1}=$ $E_{t} x_{t+1}=0$. Then, after some manipulations, it is possible to show that $\frac{\sigma_{\pi}}{\sigma_{x}}=\sqrt{\left.\frac{\left(\sigma+\rho_{x}\right)^{2} \sigma_{\varepsilon}^{2}+\kappa^{2} \sigma_{\varepsilon}^{2} M P}{\rho_{\pi}^{2} \sigma_{\varepsilon}^{2}+\sigma_{\varepsilon}^{2} M P}+\sigma^{2} \sigma_{\varepsilon}^{2}\right)_{\varepsilon}^{2} \sigma_{\varepsilon}^{2}}$. Under determinacy (i.e. $\rho_{\pi}>1$ ), this implies $\frac{\partial\left(\sigma_{\pi} / \sigma_{x}\right)}{\partial \rho_{\pi}}<0$ - for whatever admissible parameterization - which proves the statement in the text.

${ }^{11}$ The plots regarding the indeterminacy scenarios do not include the pair $\left(\sigma_{x}, \sigma_{\pi}\right)$ obtained with $\rho_{\pi}=1, \rho_{x}=$ 0 because of the out-of-scale volatility of inflation registered.
} 
with $z_{t}$ representing a generic macroeconomic variable, and $\xi_{t} \sim$ i.i.d.N $\left(0, \sigma_{\xi}^{2}\right)$. We define the degree of persistence of this process as $z_{\phi} \equiv \sum_{j=0}^{n} \phi_{j}$. Then, the unconditional volatility - measured by the standard deviation - of $z$ is

$$
\sigma_{z}=\frac{\sigma_{\xi}}{\sqrt{1-z_{\phi}}}
$$

Obviously, given the volatility of the white noise shock of the process $\xi_{t}$, the more persistent $z$, the higher its unconditional volatility $\sigma_{z}$. Then, to our purposes it is key to verify if $z_{\phi}$ increases under indeterminacy and decreases under determinacy. If so, we could argue that monetary policy affects the persistence of inflation and the output gap, and consequently their volatilities (and their volatility ratio).

We perform this check by fitting the simulated time series of inflation and the output gap with an autogregressive model as (5), and confronting the estimated persistence with the unconditional volatilities computed as described before. ${ }^{12}$

We plot our results in Figure 3 (inflation) and Figure 4 (output). Figure 3 shows an interesting positive correlation between the estimated inflation persistence and the unconditional inflation volatility when plotted against the policy parameter $\rho_{\pi} \cdot{ }^{13}$ Indeed, this plot confirms that as long as the Taylor principle is not met, the tighter the monetary policy management, the higher the inflation persistence, the higher the inflation volatility. The switch to activeness pays off, because it dramatically reduces inflation volatility, so delivering a better outcome for the Society.

\section{[insert Figure 3 about here]}

Figure 4 completes the picture. It emerges that a fairly robust correlation also characterizes the volatility and persistence of the output gap. ${ }^{14}$ Interestingly, the standard deviation of the output gap is curbed by an increase of $\rho_{\pi}$ as long as a passive monetary policy is implemented, while it is enhanced under uniqueness. It is then not surprising that the overall effect on the volatility ratio (Figure 2) is basically the opposite under the two monetary policy scenarios.

\section{[insert Figure 4 about here]}

These results offer a very new finding to the monetary policy literature regarding the mechanism linking systematic monetary policy, inflation and output persistence, and their

\footnotetext{
${ }^{12}$ We admit up to four lags for the process (5). For each OLS estimated model, the number of lags was selected according to the Schwarz's Bayesian Criterion. Of course, the dynamics expressed by the reduced form of model (1)-(3) is not necessarily captured by the simple, univariate autoregressive model we employ for measuring the persistence of the simulated series, that just represent a first approximation of it.

${ }^{13}$ Under continuity, the correlations between volatility and persistence amounts to 0.90 (top panel) and 0.83 (bottom panel). Under orthogonality, 0.87 (top panel) and 0.81 (bottom panel).

${ }^{14}$ Under continuity, the correlations between volatility and persistence amounts to 0.82 (top panel) and 0.91 (bottom panel). Under orthogonality, 0.83 (top panel) and 0.93 (bottom panel).
} 
volatilities. Interestingly, it emerges that, in case of a switch in the monetary policy regime in an otherwise unchanged model, the persistence of the inflation and output gap processes stemming from such model may vary quite significantly. This finding seems to represent a warning on the use of long-samples featured by the presence of structural policy break when estimating structural schedules. Indeed, such exercises may lead to flawed results due to model misspecification. ${ }^{15}$

\subsection{Indeterminacy and the Great Moderation}

The observations of the volatilities of the U.S. economy in the last four decades suggest that the last two decades have been featured by a much lower volatility of inflation and the output gap. Figure 5 depicts 5 -year moving averages that clearly show that, in first approximation, two regimes may be identified. In the the first regime, the average standard deviation of inflation is 2.20 , and that of the output gap is 2.68. In the second regime, such figures drop respectively to 1.00 and $2.03 .{ }^{16}$ Notice that this is not a finding one may easily explain by employing the standard Taylor curve. In fact, the volatility trade-off predicts a raise (fall) of the output gap volatility in reaction to a fall (raise) of the standard deviation of inflation.

\section{[insert Figure 5 about here]}

Interestingly, two recent contributions point towards a possible break-down of the standard inflation/output trade-off. Branch et al (2004) show that a model in which firms choose their information acquisition rate by minimizing a loss function that depends on expected forecast errors and information costs. The central bank aims at minimizing a penalty function whose arguments are the expected volatility of the cross-sectional price and that of the output gap. When moving towards a tighter policy against price fluctuations, a direct effect on the volatility of output (that increases) is exerted - but an indirect effect, channeled by a decrease of the optimal information acquisition rate - tends to reduce such volatility. It turns out that there is no trade-off between the price level stabilization and the output gap stabilization as long as the central bank's focus on the output gap stabilization is high enough. Then, the great moderation may be explained by a shift in the degree of the relative policy aggressiveness against price-level volatility. Orphanides and Williams (2004) propose a set up in which agents "perpetually" learn about the structure of the economy, i.e. agents have

\footnotetext{
${ }^{15}$ For a nice paper showing how severely biased the estimates of a Phillips curve in such context may be, see Surico (2005). A recent application by Lubik and Schorfheide (2004) shows how to deal with indeterminacy in estimating a DSGE monetary policy model, while Castelnuovo and Surico (2005) show that inflation expectations are important in SVAR analysis in sub-samples characterized by passive monetary policy.

${ }^{16}$ First regime, sample: 1966Q1-1979Q3. Second regime, sample: 1982Q4-2005Q3. The inflation rate is the annualized quarterly variation of the GDP deflator. The output gap is measured as the log-difference between real GDP and the measure of potential output of the Congressional Budget Office. The series employed in this analysis were downloaded from the Federal Reserve Bank of St. Louis website in January 2006, and are available upon request.
} 
an imperfect knowledge of the economic structure and infer about it at a constant pace via a recursive least square formula that places greater weight on more recent observations. It turns out that, for a Phillips curve in which inflation expectations have a great weight in shaping inflation realizations, and for "low enough" policymakers preferences over inflation stabilization, the inflation/output tradeoff may break down. This happens because in their model inflation expectations persistently deviate from rational expectations, so becoming a source of instability and providing an additional role for monetary policy.

The results we presented above candidate the monetary policy switch story as another (possibly complementary) explanation of the Great Moderation. Indeed, by looking at Figures 3 and 4 it is easy to realize that both volatilities fall once the central banker has moved to an aggressive enough monetary policy. Clarida et al (2000) and Lubik and Schorfheide (2004) propose estimates for the parameter $\rho_{\pi}$ of about $0.70-0.90$ for the pre-Volcker era, and close to 2 under the Volcker-Greenspan monetary policy regime. The estimates for the $\rho_{x}$ are surrounded by higher uncertainty, but the coefficient is positive and significant, above all in the Greenspan sample. By associating these estimates to the volatilities in Figures 3 and 4, it emerges that the shift from passive to active monetary policy might really represent (one of) the explanation(s) of the reduction of the macroeconomic volatilities in the last two decades in the United States.

The next Section shows how robust our findings are to some perturbations to our benchmark parameterization.

\section{Robustness Check}

We discuss here some of the robustness check we implemented. First, we enrich the Taylor rule (3) with an interest rate smoothing argument, i.e. we consider the rule

$$
R_{t}=(1-\rho)\left(\rho_{\pi} \pi_{t}+\rho_{y} x_{t}\right)+\rho R_{t-1}+\varepsilon_{t}^{M P}
$$

The empirical relevance of the lagged coefficient in the Taylor rule has been supported e.g. by Clarida et al (2000). In line with several empirical contributions, we set the degree of interest rate smoothing at a high value, i.e. $\rho=0.7$. The results turn out to be qualitatively in line with the ones presented above. Interestingly, a comparison between Figures 2 vs. 6 and 3 vs. 7 highlights the role played by the interest rate smoothing in influencing inflation expectations and reducing the volatility of inflation (while slightly augmenting that of the output gap), an effect already discussed by e.g. Woodford (2003). ${ }^{17}$ As a second empirical check, we substituted the Taylor rule (3) with its deterministic counterpart, i.e. we set $\sigma_{\varepsilon^{M P}}^{2}=$

\footnotetext{
${ }^{17}$ The computation of the loss function $L=\sigma_{\pi}+\lambda_{y} \sigma_{y}$ for various scenarios under analysis confirmed that, for values of $\lambda_{y}$ belonging to the $[0,0.5]$ interval, the interest rate smoothing effect is beneficial for the Society both under continuity and under orthogonality.
} 
0. We did so to line up with the contributions computing the Taylor curves either under optimal monetary policy (typically not embedding a policy shock) or deterministic simple rules. Figures 10-13 depict the results under this hypothesis. The results confirm what already discuss. As a further check concerning the policy rule, we modified it in order to enable policymakers to react to expected inflation fluctuations, i.e.

$$
R_{t}=\rho_{\pi} E_{t} \pi_{t+1}+\rho_{y} x_{t}+\varepsilon_{t}^{M P}
$$

Once more, the qualitative messages of the paper turn out to be robust (see Figures 1417). Another perturbation we tried is that of the coefficient of relative risk aversion $\sigma$, whose benchmark value is equal to 1 . We set it equal to 5 , and remade our simulations. ${ }^{18}$ Figures 18-21 seem to confirm our main results. Finally, given the huge uncertainty surrounding the importance of automatic adjustments for the formation of inflation, we repeat our simulations with a much lower value for the share of the firms who automatically adjust their prices when not allowed to reoptimize, i.e. $w=0.3$. Figures $22-25$ confirm the robustness of our findings.

\section{[insert Figures 6-25 about here]}

\section{Conclusions}

If monetary policymakers react too weakly to inflation oscillations and the Taylor principle is not met, sunspot fluctuations of the macroeconomic variables may arise. In this scenario, the inflation/output volatility works in a very particular manner, i.e. the inflation/volatility ratio raises when the monetary policy becomes more aggressive. The reason for this results is likely to be the impact that monetary policy has on inflation and output persistence. Under indeterminacy, such an influence is positive, i.e. the more aggressive the central bank, the more persistent inflation, and the less persistent the output gap. Under determinacy, it happens right the opposite. This result may then explain our finding on the inflation/volatility ratio, and is qualitatively in line with the facts regarding the observed volatilities and volatility ratios in the U.S. (as well as other industrialized countries).

We think our findings call for a better understanding of the macroeconomic behavior under passive monetary policy. Recent contributions by Fuhrer (2005) and Angeloni et al (2005) discuss different possible sources of the inflation persistence. This paper candidates sunspot fluctuations as a main driver of inflation in specific subsamples, and underlines the importance of relating the persistence of inflation to the monetary policy conduct. The fact that under different policy regimes the persistence of the main macroeconomic series may dramatically

\footnotetext{
${ }^{18}$ Such value for the relative risk aversion implies that the inverse of the sacrifice ratio is $\kappa=0.1650$, much more in line with some of the estimates in the literature.
} 
change seems to be a warning on the reliability of the econometric results obtained with long samples incorporating different, regime-specific sub-samples.

\section{References}

Angeloni, I., L. Aucremanne, M. Ehrmann, J. Galí, A. Levin, and F. Smets, 2005, New evidence on inflation persistence and price stickiness in the Euro Area: Implications for Macro Modelling, Journal of the European Economic Association, forthcoming.

Bernanke, B., 2004, The Great Moderation, remarks at the meetings of the Eastern Economic Association, Washington, DC, February 20.

Boivin, J., and M. Giannoni, 2003, Has Monetary Policy Become More Effective?, NBER Working Paper No. 9459, January.

Branch, W.A., J. Carlson, G.W. Evans, and B. McGough, 2004, Monetary policy, endogenous inattention, and the volatility trade-off, mimeo, December.

Castelnuovo and Surico, 2005, The Price Puzzle: Fact or Artifact? Bank of England Working Papers Series, forthcoming.

Christiano, L., M. Eichenbaum, and C. Evans, 2005, Nominal rigidities and the dynamic effect of a shock to monetary policy, Journal of Political Economy, 113, 1-45.

Clarida, R., J. Galí, and M. Gertler, 2000, Monetary Policy Rules and Macroeconomic Stability: Evidence and Some Theory, The Quarterly Journal of Economics, 115(1), $147-180$

Cogley, T., and T. J. Sargent, 2005, Drift and Volatilities: Monetary Policies and Outcomes in the Post WWII US, Review of Economic Dynamics, forthcoming.

Dennis, R., 2005, Specifying and estimating new Keynesian models with instrument rules and optimal monetary policy, Federal Reserve Bank of San Francisco Working Paper Series No. 2004-17.

Fuhrer, J.C., 2005, Intrinsic and Inherited Inflation Persistence, Federal Reserve Bank of Boston Working Paper, No. 05-8.

Fuhrer, J.C., and G.D. Rudebusch, 2004, Estimating the Euler Equation for Output, Journal of Monetary Economics, 51(6), 1133-1153, September.

Galì, J., M. Gertler, and J.D. López-Salido, 2001, European inflation dynamics, European Economic Review, 45, 1237-1270.

Galì, J., M. Gertler, and J.D. López-Salido, 2003, Erratum to "European inflation dynamics", European Economic Review, 47, 759-760.

Ireland, P., 2004, Technology shocks in the new Keynesian model, Review of Economics and Statistics, 86(4), 923-936, November.

Lubik, T.A., and F. Schorfheide, 2003, Computing Sunspot Equilibria in Linear Rational Expectations Models, Journal of Economic Dynamics and Control, 28(2), 273-285. 
Lubik, T.A., and F. Schorfheide, 2004, Testing for Indeterminacy: An Application to US Monetary Policy, The American Economic Review, 94(1), 190-217.

Orphanides, A., and J.C. Williams, 2004, Imperfect Knowledge, Inflation Expectations, and Monetary Policy, in B. Bernanke, and M. Woodford (eds.), The inflation targeting debate, Chicago: University of Chicago Press.

Rabanal, P., 2006, Does inflation increase after a monetary policy tightening? Some answers based on an estimated DSGE model, mimeo.

Sims, C.A., and T. Zha, 2005, Were there regime switches in US monetary policy?, The American Economic Review, forthcoming.

Surico, P., 2005, Monetary Policy Shifts, Indeterminacy and Inflation Dynamics, Bank of England and University of Bari, mimeo.

Taylor, J.B., 1979, Estimation and control of a macroeconomic model with rational expectations, Econometrica, 47(5), 1267-1286, September.

Taylor, J.B., 1993, Discretion Versus Policy Rules in Practice, Carnegie-Rochester Series on Public Policy, 39, 195-214.

Taylor, J.B., 1999, Monetary policy rules, NBER Conference Report series, Chicago and London: University of Chicago Press.

Woodford, M., 2003, Interest and Prices: Foundation of a Theory of Monetary Policy, Princeton University Press. 

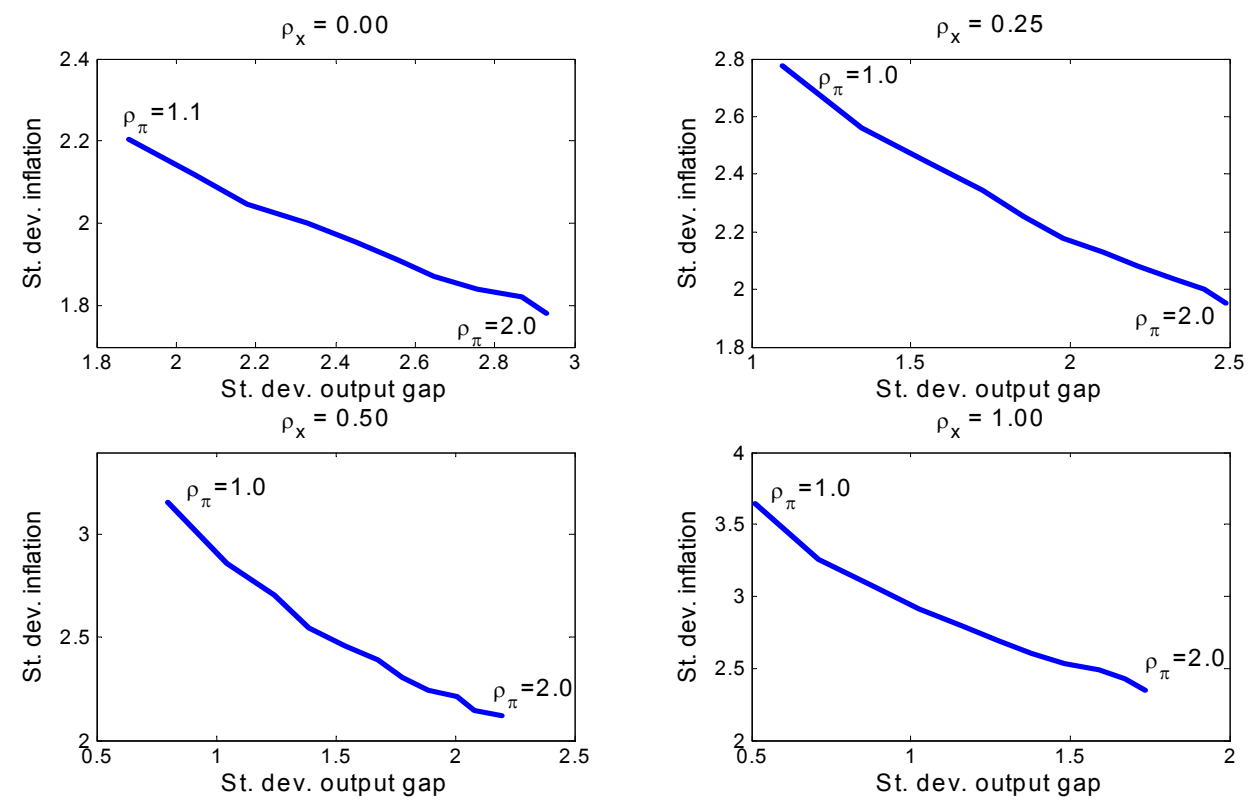

Figure 1. Taylor curves under uniqueness: Benchmark Model. Parameterization described in the text
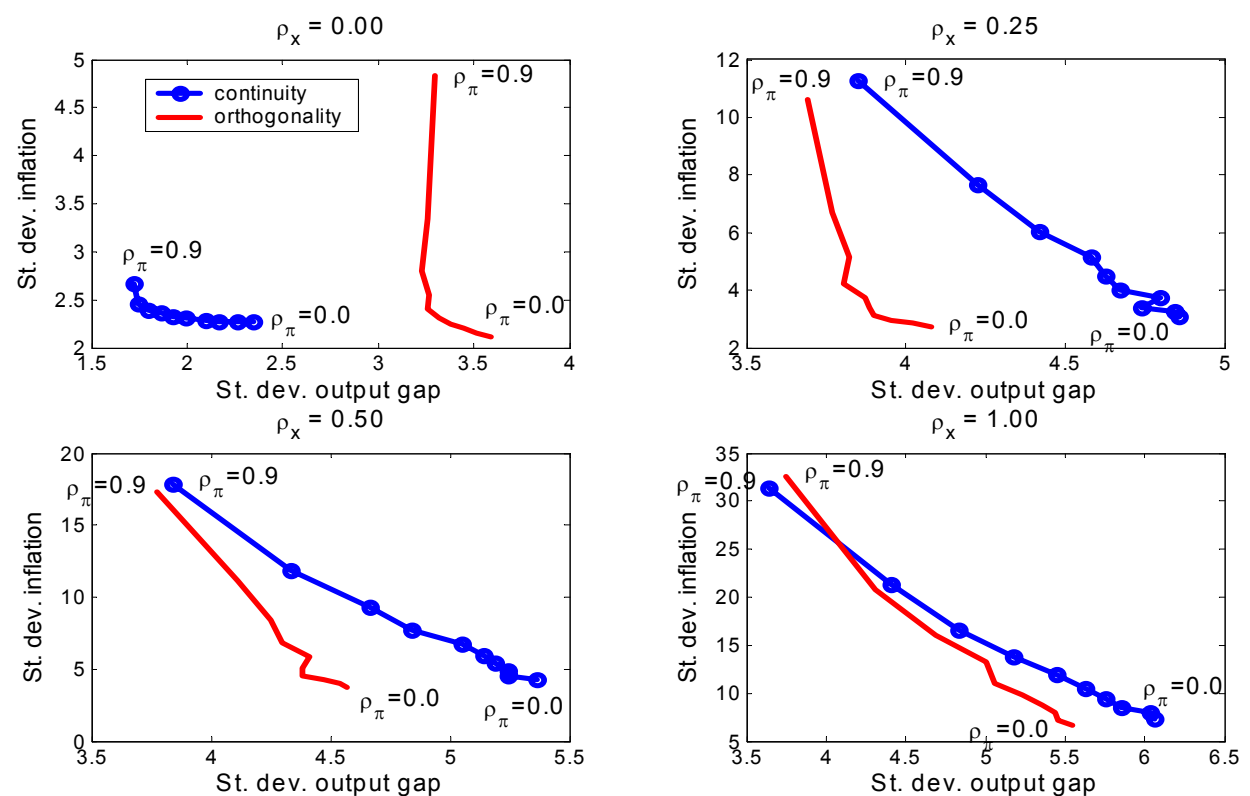

Figure 2. Taylor curves under indeterminacy: Benchmark model. Parameterization as indicated in the text. 

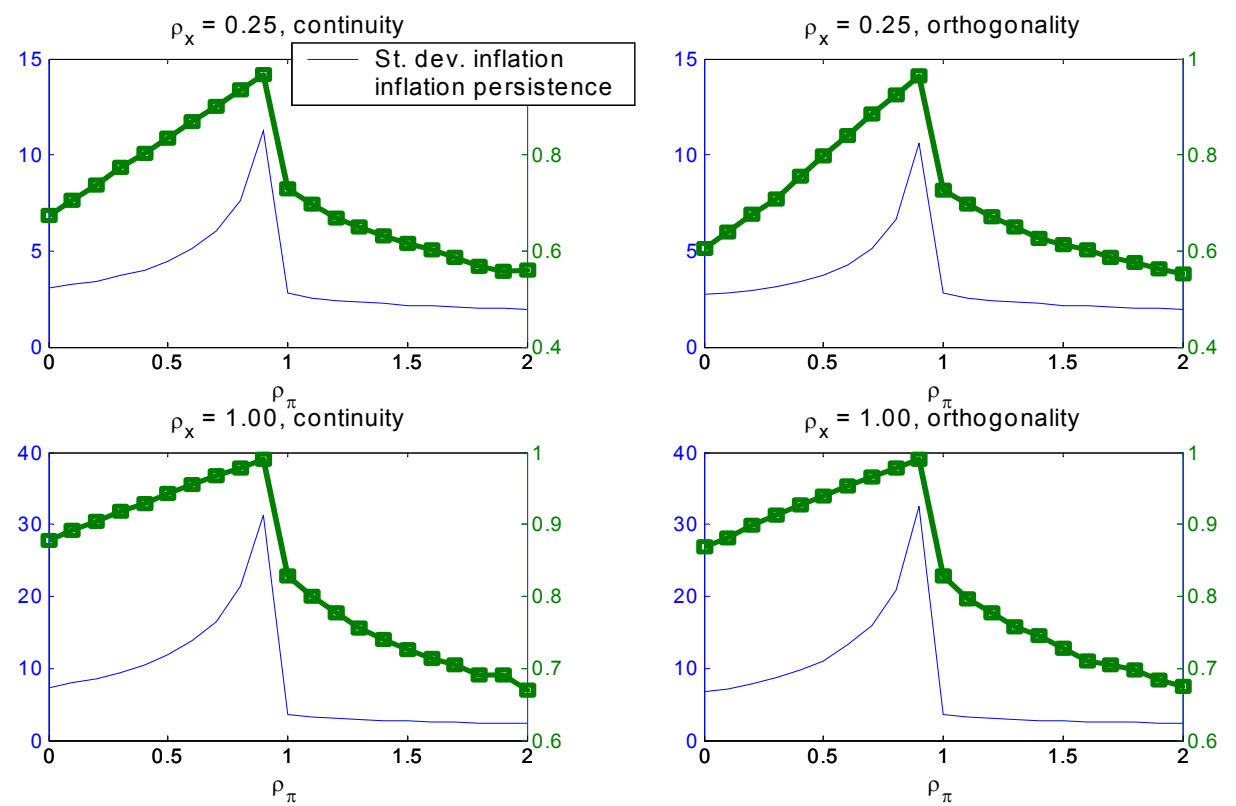

Figure 3. Inflation volatility/persistence vs. policy parameter $\rho_{\pi}$. Left y-axis: Standard deviation of inflation; right y-axis: Inflation persistence.
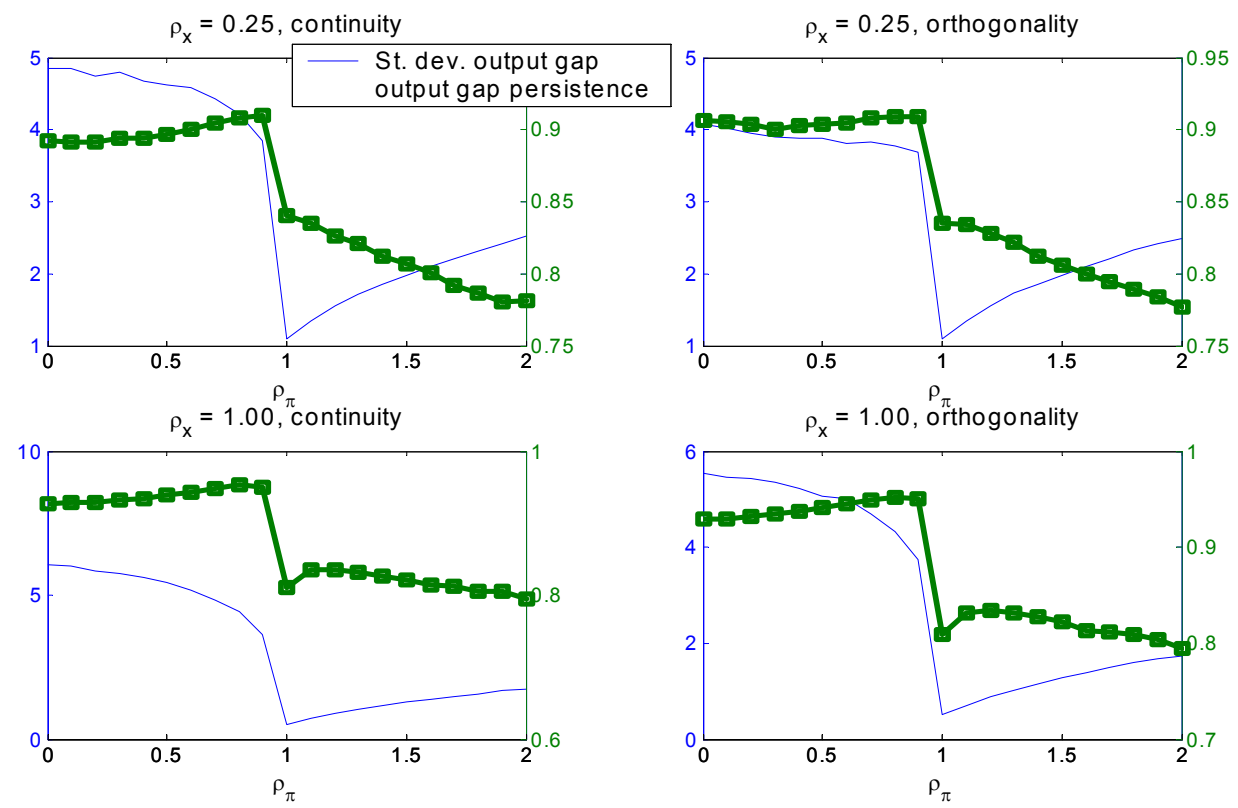

Figure 4. Output gap volatility/persistence vs. policy parameter $\rho_{\pi}$. Left y-axis: Standard deviation of the output gap; right y-axis: Output gap persistence. 

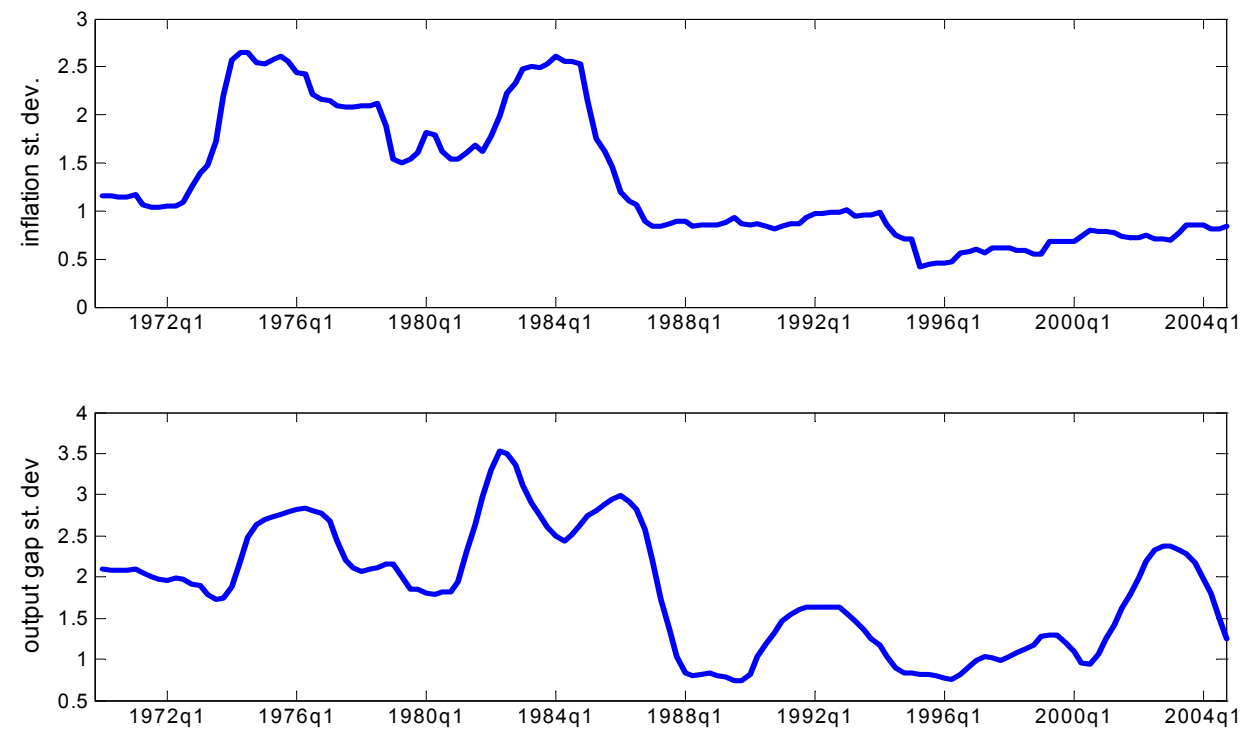

Figure 5. Volatility of inflation and the output gap, sample: 1966Q1-2005Q3. Standard deviations computed as 5-year moving averages (rolling windows). The $\mathrm{x}$-axis reports the last quarter of some of the 5 -year windows employed in the computation of the standard deviations. 


\section{Technical Appendix: Solution of the LRE Model}

The linear rational expectations model described by equations (1)-(3) can be cast in the following canonical form:

$$
\Gamma_{0}(\theta) s_{t}=\Gamma_{1}(\theta) s_{t-1}+\Psi(\theta) \varepsilon_{t}+\Pi(\theta) \eta_{t}
$$

where the vector $s_{t}=\left[x_{t}, \pi_{t}, R_{t}, E_{t} x_{t+1}, E_{t} \pi_{t+1}\right]^{\prime}$ collects the $n$ variables of the system, $\varepsilon_{t}=$ $\left[\varepsilon_{t}^{M P}, \varepsilon_{t}^{\pi}, \varepsilon_{t}^{x}\right]^{\prime}$ is the vector of $l$ fundamental shocks, $\eta_{t}=\left[\left(x_{t}-E_{t-1} x_{t}\right),\left(\pi_{t}-E_{t-1} \pi_{t}\right)\right]^{\prime}$ collects the $k$ rational expectations forecast errors, and $\theta=\left[\rho_{\pi}, \rho_{x}, \rho, \beta, w, \kappa, b, \sigma, \sigma_{\varepsilon^{\pi}}^{2}, \sigma_{\varepsilon^{x}}^{2}\right]$ is the vector of the parameters of the model outlined in the previous section.

In order to transform the canonical form and solve the model, we follow Sims (2001) and exploit the generalized complex Schur decomposition $(Q Z)$ of the matrices $\Gamma_{0}$ and $\Gamma_{1}$. This corresponds to computing the matrices $Q, Z, \Lambda$ and $\Delta$ such that $Q Q^{\prime}=Z Z^{\prime}=I_{n}, \Lambda$ and $\Delta$ are upper triangular, $\Gamma_{0}=Q^{\prime} \Lambda Z$ and $\Gamma_{1}=Q^{\prime} \Delta Z$. Defining $w_{t}=Z^{\prime} s_{t}$ and pre-multiplying (7) by $Q$, we obtain:

$$
\left[\begin{array}{cc}
\Lambda_{11} & \Lambda_{12} \\
0 & \Lambda_{22}
\end{array}\right]\left[\begin{array}{l}
w_{1, t} \\
w_{2, t}
\end{array}\right]=\left[\begin{array}{cc}
\Delta_{11} & \Delta_{12} \\
0 & \Delta_{22}
\end{array}\right]\left[\begin{array}{l}
w_{1, t-1} \\
w_{2, t-1}
\end{array}\right]+\left[\begin{array}{l}
Q_{1} \\
Q_{2}
\end{array}\right]\left(\Psi \varepsilon_{t}+\Pi \eta_{t}\right)
$$

where, without loss of generality, the vector of generalized eigenvalues $\lambda$, which is the vector of the ratios between the diagonal elements of $\Delta$ and $\Lambda$, has been partitioned such that the lower block collects all the explosive eigenvalues. The matrices $\Delta, \Lambda$ and $Q$ have been partitioned accordingly, and therefore $Q_{j}$. collects the blocks of rows that correspond to the stable $(j=1)$ and unstable $(j=2)$ eigenvalues respectively.

The explosive block of (8) can be rewritten as: ${ }^{19}$

$$
w_{2, t}=\Lambda_{22}^{-1} \Delta_{22} w_{2, t-1}+\Lambda_{22}^{-1} Q_{2 .}\left(\Psi \varepsilon_{t}+\Pi \eta_{t}\right)
$$

Given the set of $m$ equations (9), a non-explosive solution of the linear rational expectations model (7) for $s_{t}$ requires $w_{2, t}=0 \forall t \geq 0$. This can be obtained by setting $w_{2,0}=0$ and choosing for every vector $\varepsilon_{t}$ the endogenous forecast error $\eta_{t}$ that satisfies the following condition

$$
Q_{2 .}\left(\Psi \varepsilon_{t}+\Pi \eta_{t}\right)=0
$$

A general stable solution for the endogenous forecast error can be computed through a singular value decomposition of $\underbrace{Q_{2 .} \Pi}_{m x k}=\underbrace{U}_{m x m m x k} \underbrace{D}_{k x k} V^{\prime}=\underbrace{U_{r x r}}_{m x r} \underbrace{D_{11}}_{r x k} V_{.1}^{\prime}$, where $D_{11}$ is a diagonal matrix

\footnotetext{
${ }^{19}$ It is possible to have some zero-elements on the main diagonal of $\Lambda_{22}$. In this case, the latter matrix is not invertible. The 'solving-forward' solution proposed by Sims (2001) and extended by Lubik and Schorfheide (2003) overcomes this problem. A Technical Appendix with a more detailed discussion of the solution strategy is available from the authors upon request.
} 
and $D$ and $U$ are orthonormal matrices. Using this decomposition, Lubik and Schorfheide (2003) show that in equilibrium the vector of endogenous forecast errors reads as follows:

$$
\eta_{t}=\left(-V_{.1}^{\prime} D_{11}^{-1} U_{.1} Q_{2 .} \Psi+V_{.2} \widetilde{M}\right) \varepsilon_{t}+V_{.2} \zeta_{t}
$$

where $\widetilde{M}$ is the $(k-r) x l$ matrix governing the influence of the sunspot shock on the model dynamics.

Assuming that $\Gamma_{0}^{-1}$ exists, the solution (11) can be combined with (7) to yield the following law of motion for the state vector:

$$
s_{t}=\Gamma_{1}^{*} s_{t-1}+\left[\Psi^{*}-\Pi^{*} V_{.1} D_{11}^{-1} U_{.1}^{\prime} Q_{2 .} \Psi+\Pi^{*} V_{.2} \widetilde{M}\right] \varepsilon_{t}+\Pi^{*} V_{.2} \zeta_{t}
$$

where a generic $X^{*}=\Gamma_{0}^{-1} X$.

In general, we can be confronted with three cases. If the number of endogenous forecast errors $k$ is equal to the number of nonzero singular values $r$, the system is determined and the stability condition (10) uniquely determines $\eta_{t}$. In such a case, $V_{.2}=0$, then the last two addends of (12) drop out. This implies that the dynamics of $s_{t}$ is purely a function of the structural parameters $\theta$.

If the number of endogenous forecast errors $k$ exceeds the number of nonzero singular values $r$, the system is indeterminate and sunspot fluctuations can arise. Lubik and Schorfheide (2003) show that this can influence the solution along two dimensions. First, sunspot fluctuations $\zeta_{t}$ can affect the equilibrium dynamics. Second, the transmission of fundamental shocks $\varepsilon_{t}$ is no longer uniquely identified as the elements of $\widetilde{M}$ are not pinned down by the structure of the linear rational expectations model.

Alternatively, the number of endogenous forecast errors $k$ can be smaller than the number of nonzero singular values $r$, and then the system has no solutions. These three conditions generalize the procedure in Blanchard and Kahn (1980) of counting the number of unstable roots and predetermined variables. ${ }^{20}$

In order to compute $\widetilde{M}$ and then the solutions of the model under indeterminacy, it is necessary to impose some additional restrictions on the endogenous forecast errors. Following Lubik and Schorfheide (2004), we choose $\widetilde{M}$ such that the impulse responses $\frac{\partial s_{t}}{\partial \varepsilon_{t}^{\prime}}$ associated with the system (12) are continuous at the boundary between the determinacy and the indeterminacy region. This solution is labelled "continuity". As an alternative, we compute the solution of the model under indeterminacy by imposing $\widetilde{M}=0$ can be computed using the assumption that the effects of the sunspot shocks are orthogonal to the effects of the structural shocks. This identification yields results, not reported but available upon request, that are qualitatively similar to the findings for the continuity case.

\footnotetext{
${ }^{20}$ The solution method proposed by Sims (2001) has the advantage that it does not require the separation of predetermined variables from "jump" variables. Rather, it recognizes that in equilibrium models expectational residuals are attached to equations and that the structure of the coefficient matrices in the canonical form implicitly selects the linear combination of variables that needs to be predetermined for a solution to exist.
} 
Let $\Theta^{I}$ and $\Theta^{D}$ be the sets of all possible vectors of parameters $\theta^{\prime} s$ in the indeterminacy and determinacy region respectively. For every vector $\theta \in \Theta^{I}$ we identify a corresponding vector $\tilde{\theta} \in \Theta^{D}$ that lies on the boundary of the two regions and choose $\widetilde{M}$ such that the response of $s_{t}$ to $\varepsilon_{t}$ conditional on $\theta$ mimics the response conditional on $\tilde{\theta}$. This corresponds to requiring that the condition

$$
\frac{\partial s_{t}}{\partial \varepsilon_{t}^{\prime}}(\theta)=B_{1}(\theta)+B_{2}(\theta)=\Psi^{*}-\Pi^{*} V_{.1} D_{11}^{-1} U_{.1}^{\prime} Q_{2 .} \Psi+\Pi^{*} V_{.2} \widetilde{M}
$$

be as close as possible to the condition

$$
\frac{\partial s_{t}}{\partial \varepsilon_{t}^{\prime}}(\widetilde{\theta})=B_{1}(\widetilde{\theta})
$$

Applying a least-square criterion, we can then compute

$$
\widetilde{M}=\left[B_{2}^{\prime}(\theta) B_{2}(\theta)\right]^{-1} B_{2}^{\prime}(\theta)\left[B_{1}(\widetilde{\theta})-B_{1}(\theta)\right]
$$

and use (15) to calculate the solution of the model in (11) and (12).

The new vector $\tilde{\theta}$ is obtained from $\theta$ by replacing $\rho_{\pi}$ with the condition that marks the boundary between the determinacy and indeterminacy region in the system (1)-(3). Woodford (2003) shows that this condition corresponds to the following interest rate reaction to inflation

$$
\widetilde{\rho_{\pi}}=1-\frac{(1-\beta)}{\kappa} \rho_{x}
$$

\section{Contributions cited in this Technical Appendix}

Lubik, T.A., and F. Schorfheide, 2003, Computing Sunspot Equilibria in Linear Rational Expectations Models, Journal of Economic Dynamics and Control, 28(2), 273-285.

Lubik, T.A., and F. Schorfheide, 2004, Testing for Indeterminacy: An Application to US Monetary Policy, The American Economic Review, 94(1), 190-217.

Sims, C.A., 2001, Solving Linear Rational Expectations Models, Computational Economics, 20, 1-20. 

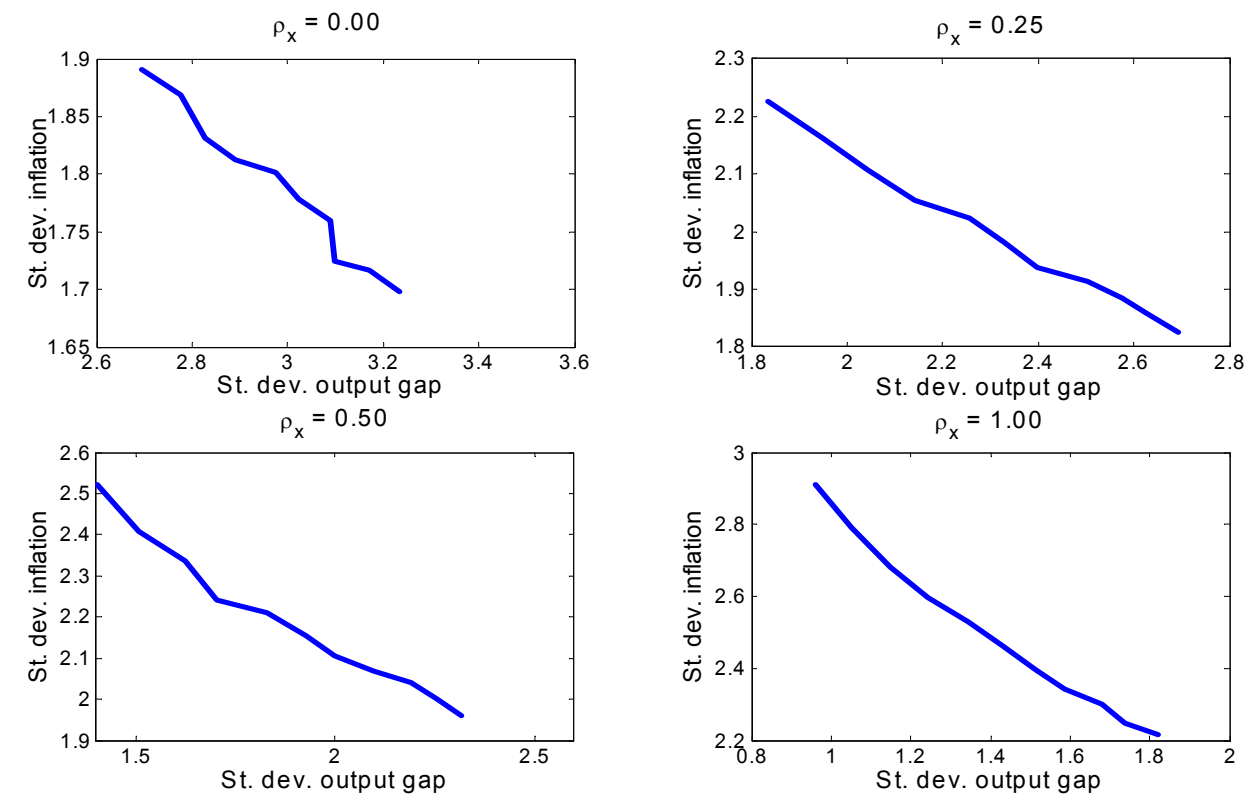

Figure 6. Robustness check, interest rate smoothing. $[\rho=0.7]$
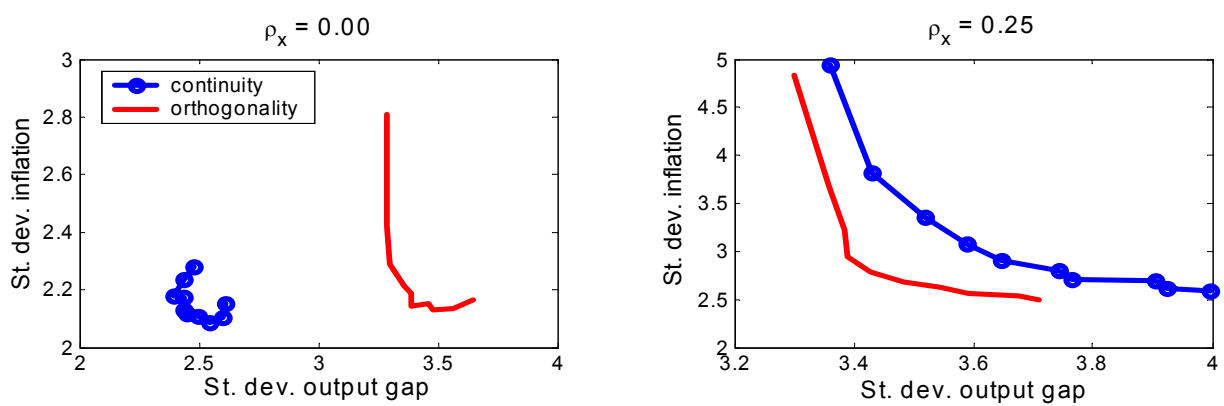

$\rho_{\mathrm{x}}=0.50$

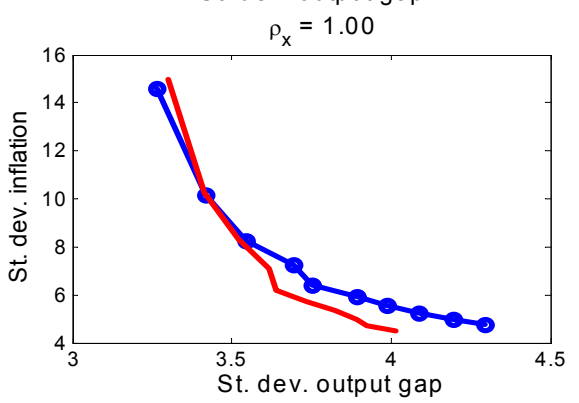

Figure 7. Robustness check, interest rate smoothing. $[\rho=0.7]$ 

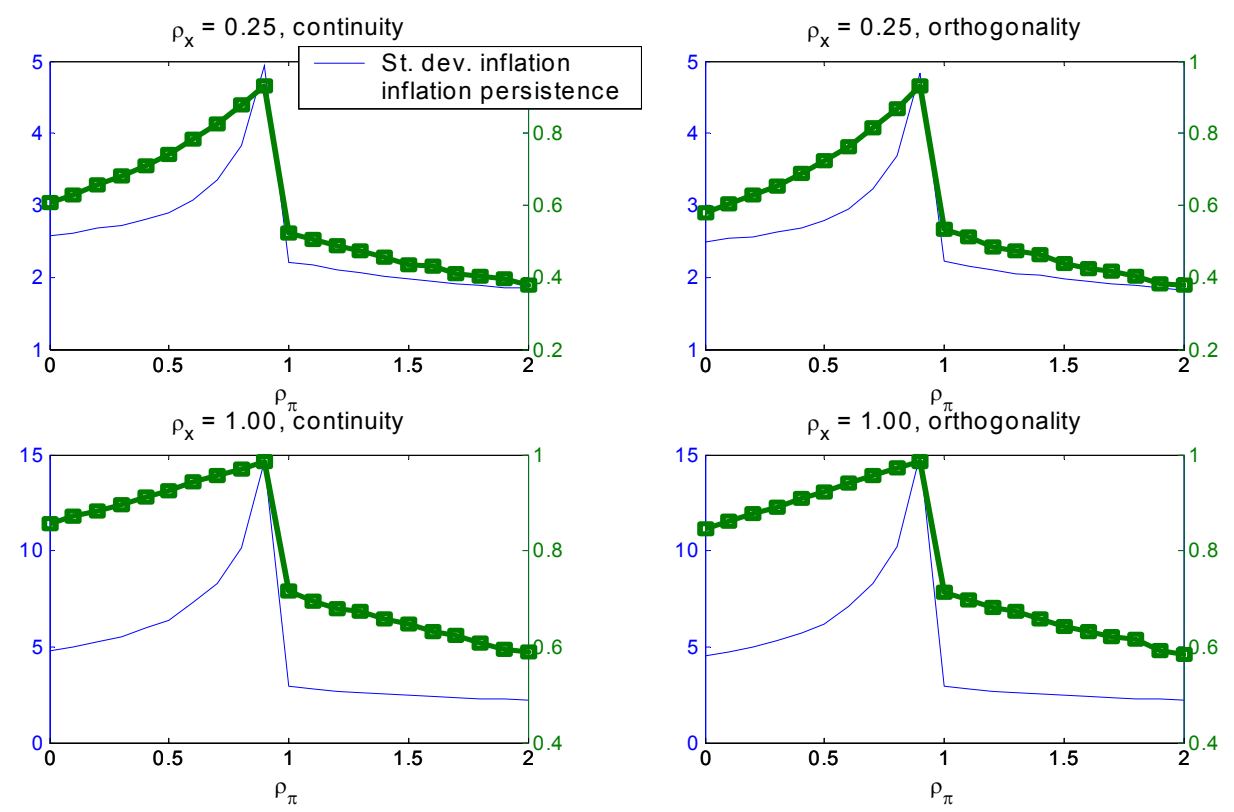

Figure 8. Robustness check with interest rate smoothing. $[\rho=0.7]$
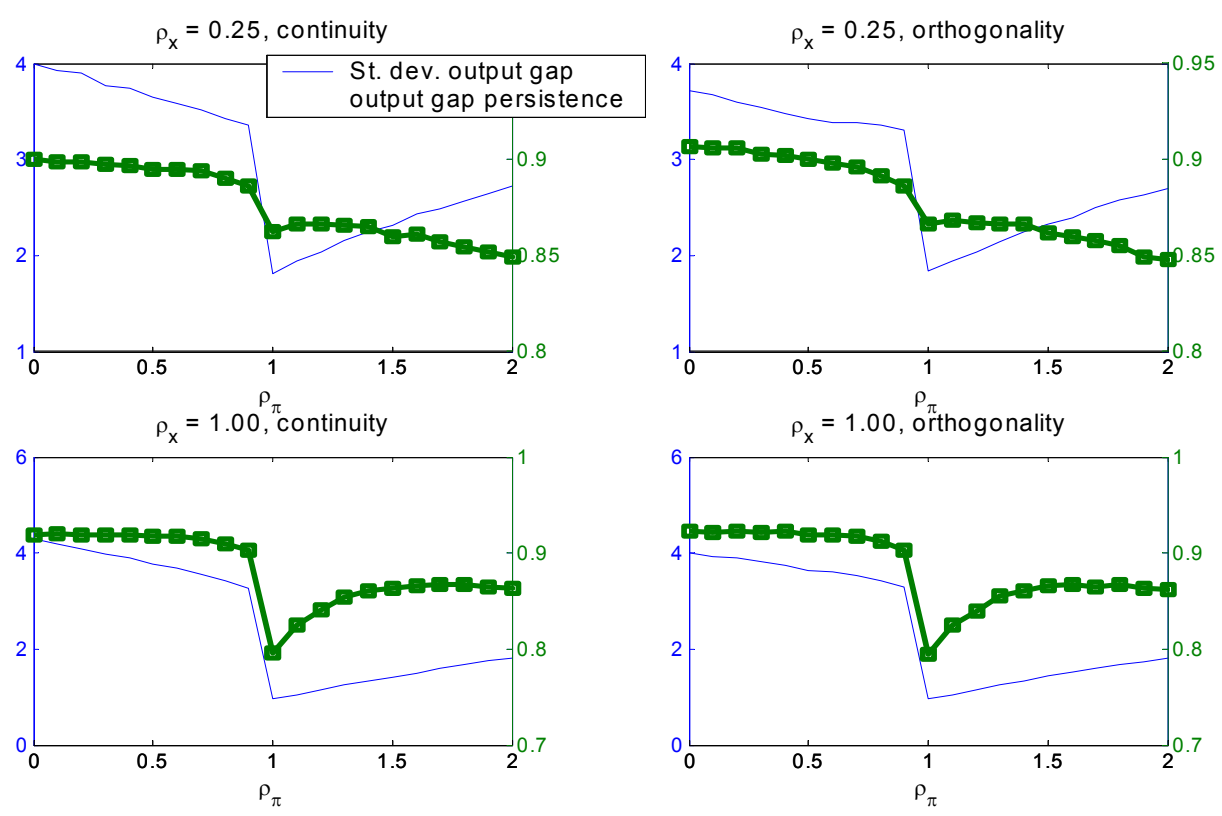

Figure 9. Robustness check with interest rate smoothing. $[\rho=0.7]$ 

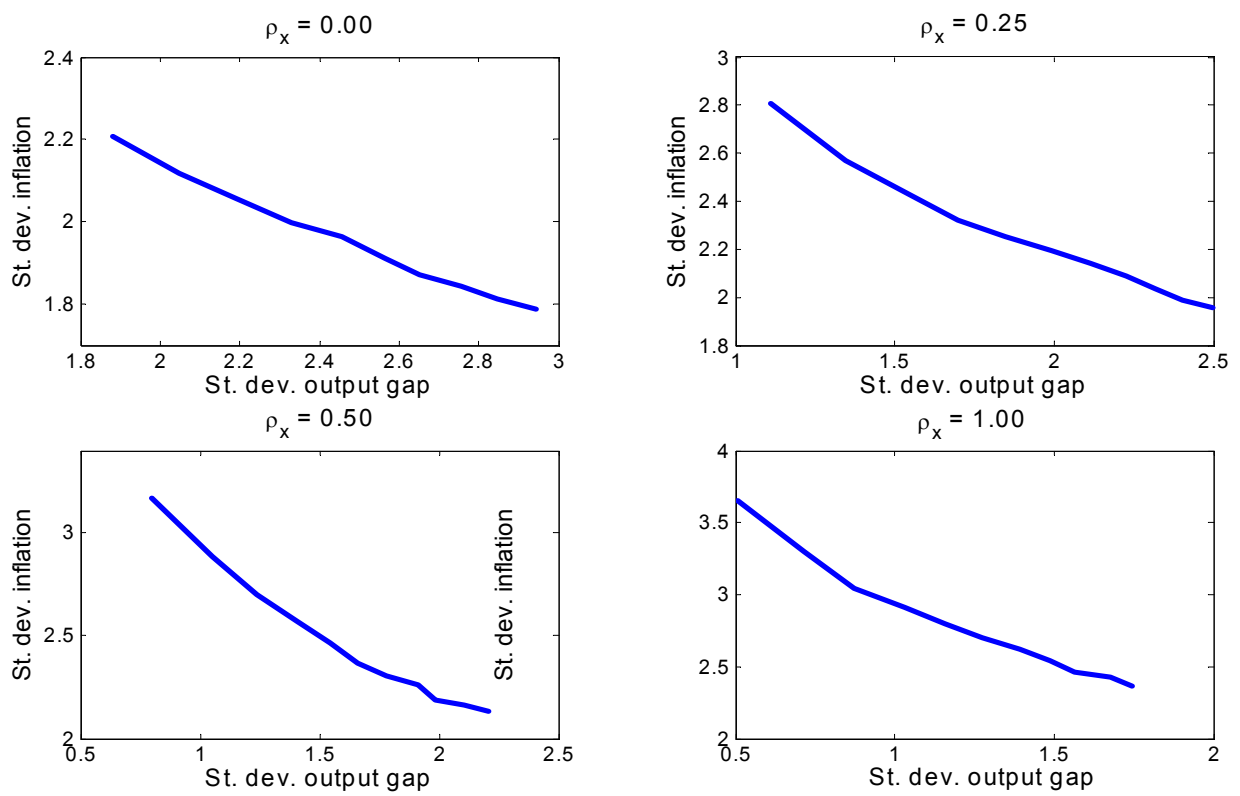

Figure 10. Robustness check with determinist Taylor rule. $\left[\sigma_{\varepsilon}^{M P}=0\right]$
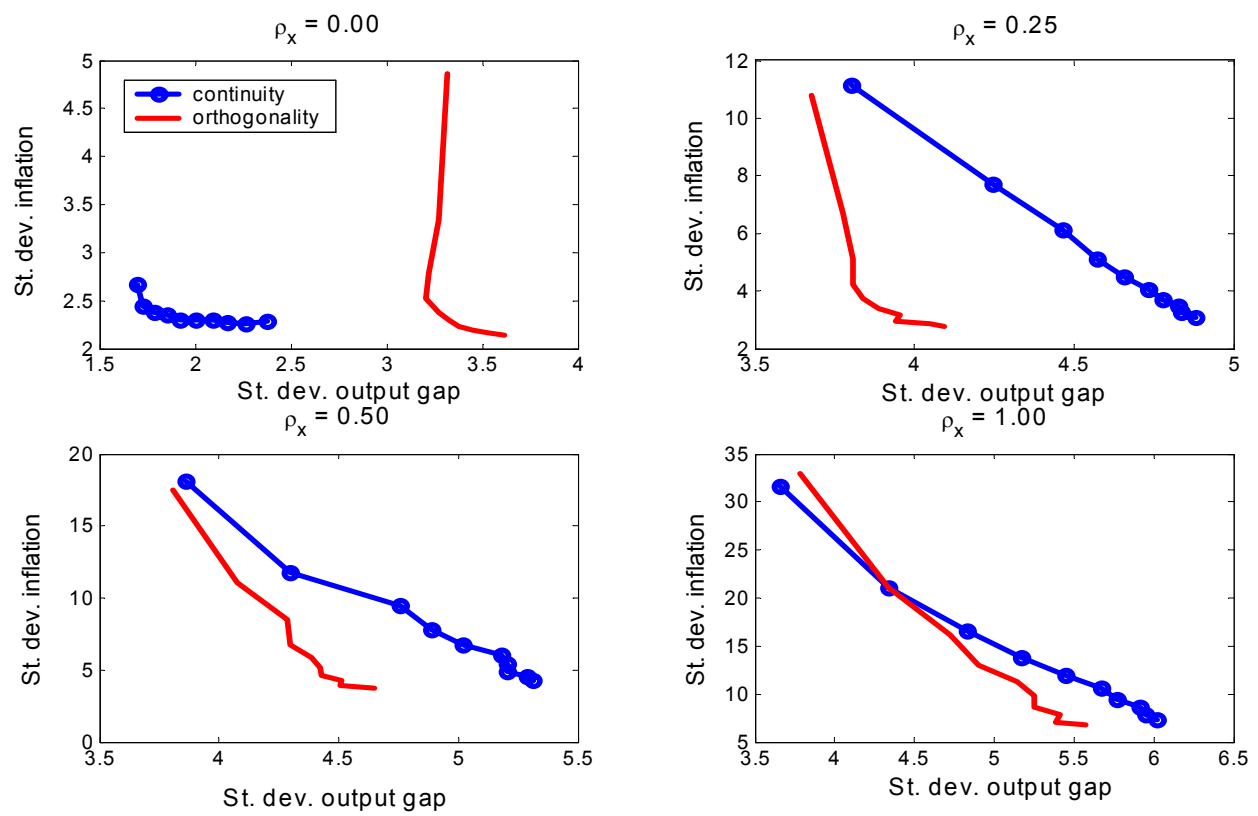

Figure 11. Robustness check with determinist Taylor rule. $\left[\sigma_{\varepsilon}^{M P}=0\right]$ 


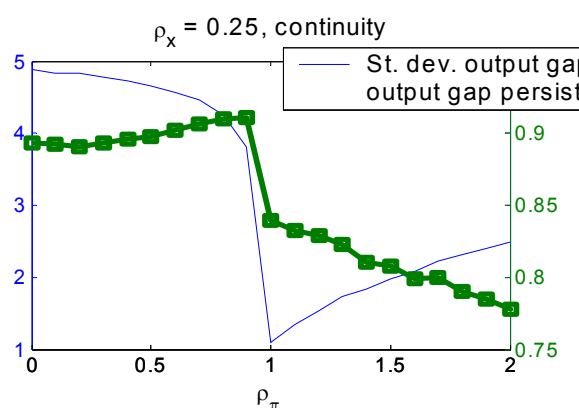

$\rho_{x}=1.00$, continuity

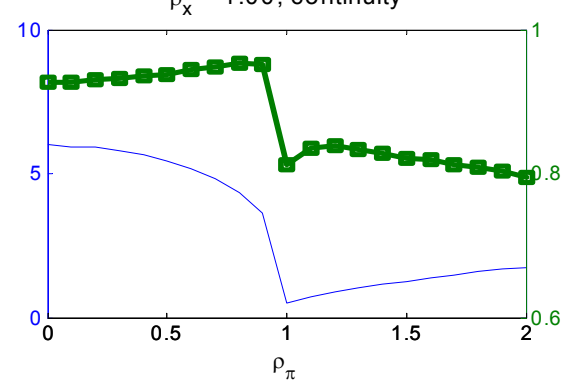

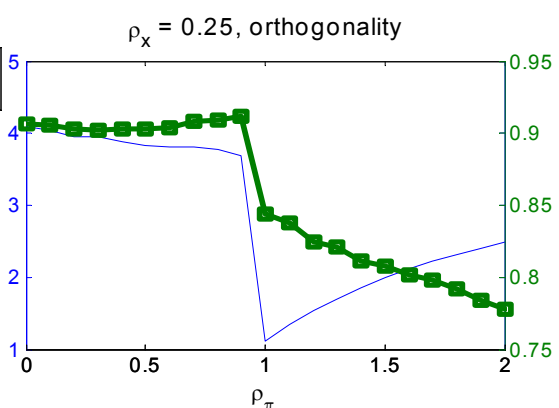

$\rho_{x}=1.00$, orthogonality

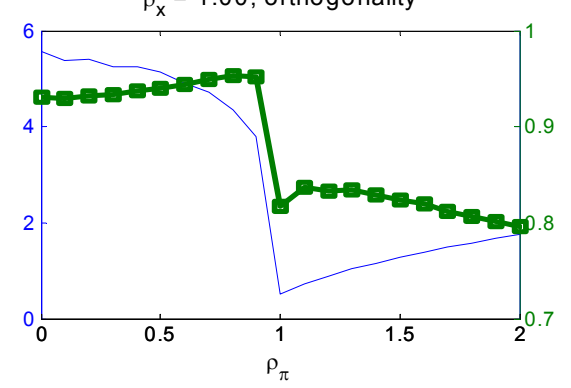

Figure 1: Figure 13. Robustness check with determinist Taylor rule. $\left[\sigma_{\varepsilon}^{M P}=0\right]$
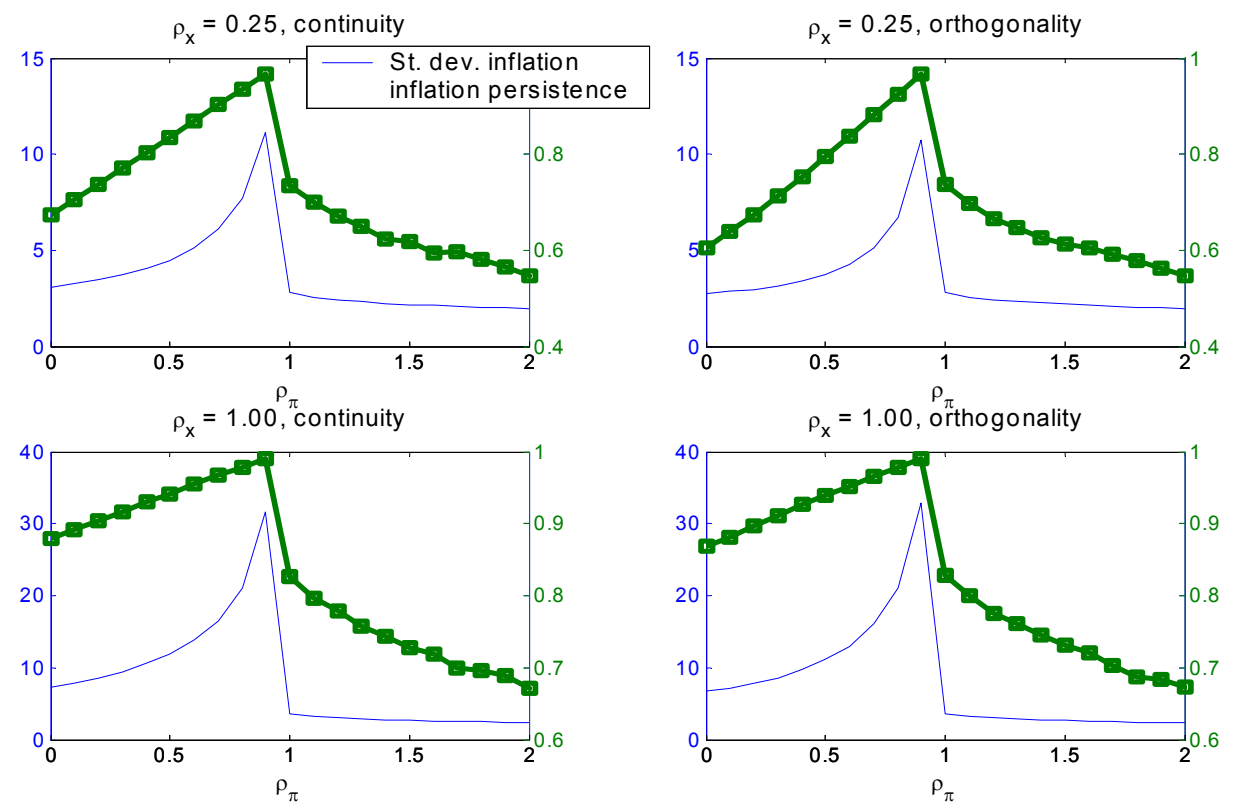

Figure 12. Robustness check with determinist Taylor rule. $\left[\sigma_{\varepsilon}^{M P}=0\right]$ 

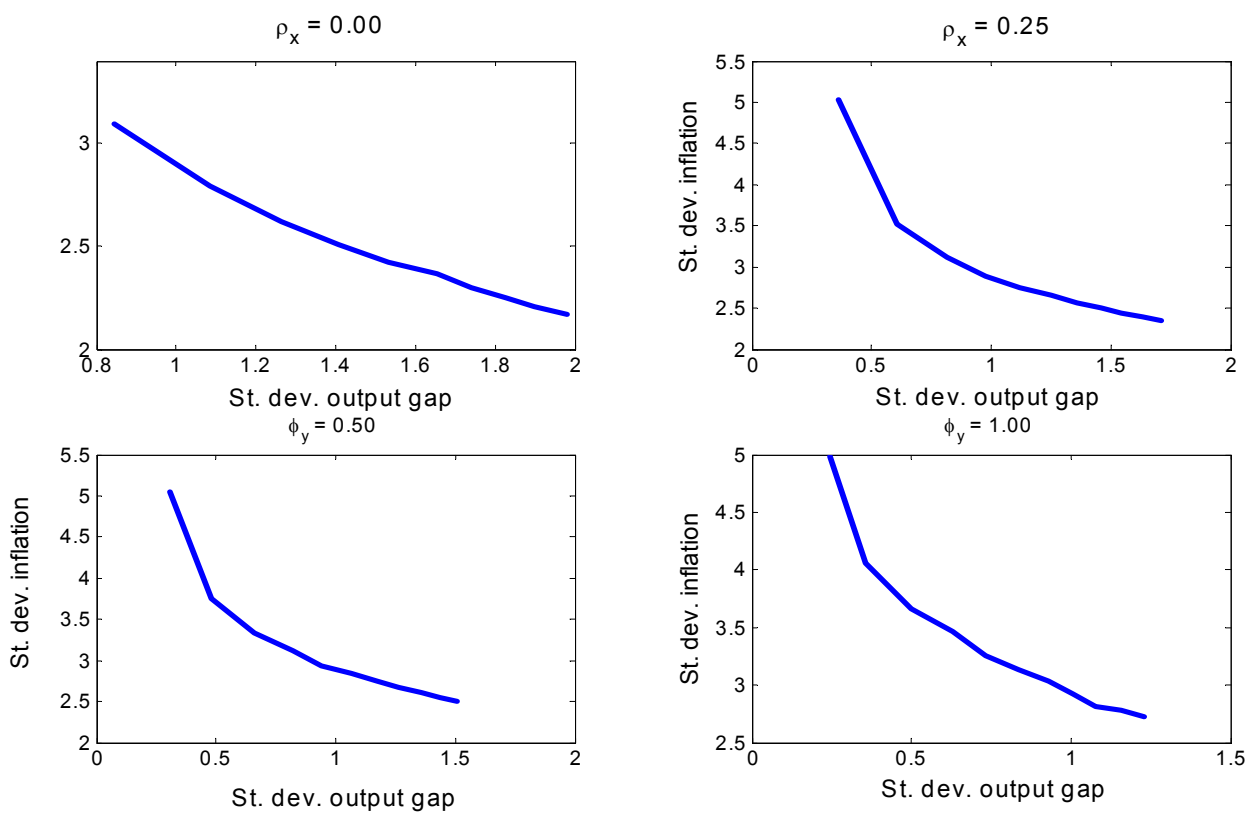

Figure 14. Robustness check with forward looking Taylor rule.
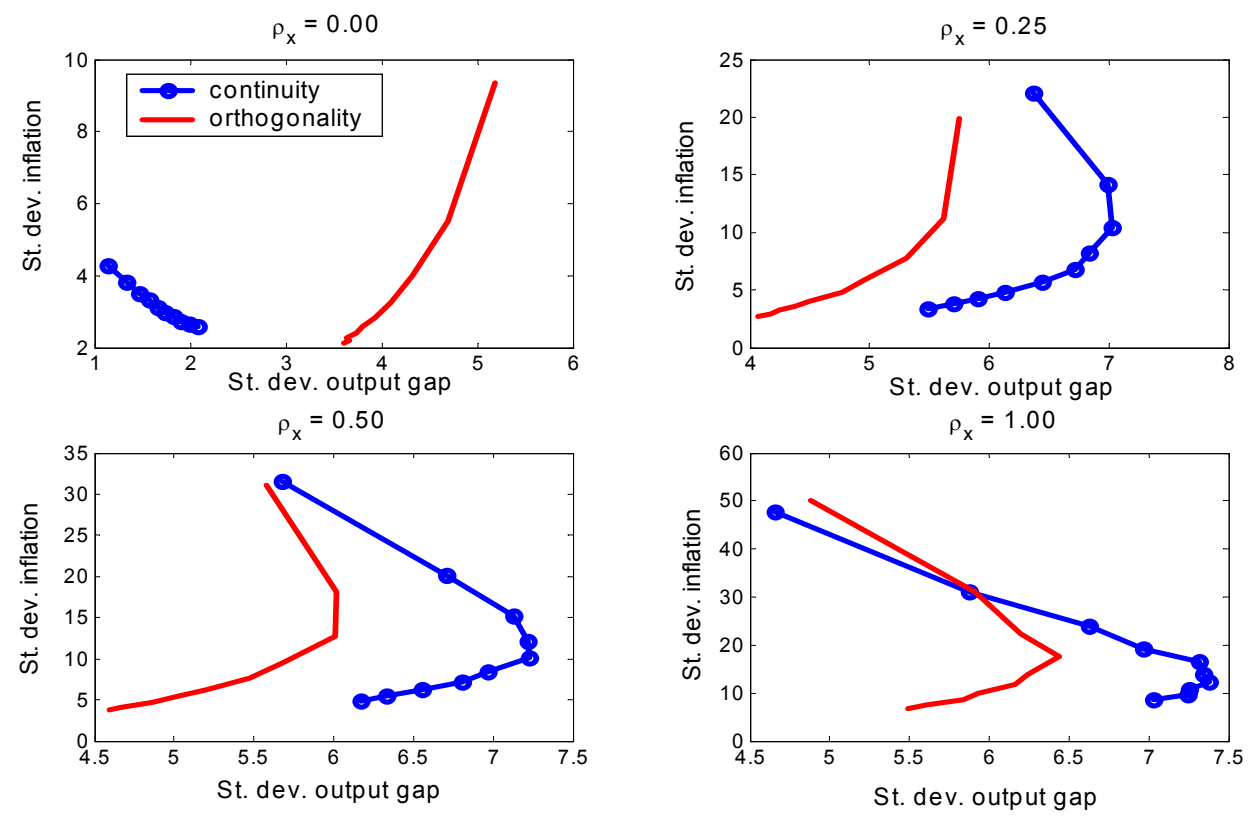

Figure 15. Robustness check with forward looking Taylor rule. 

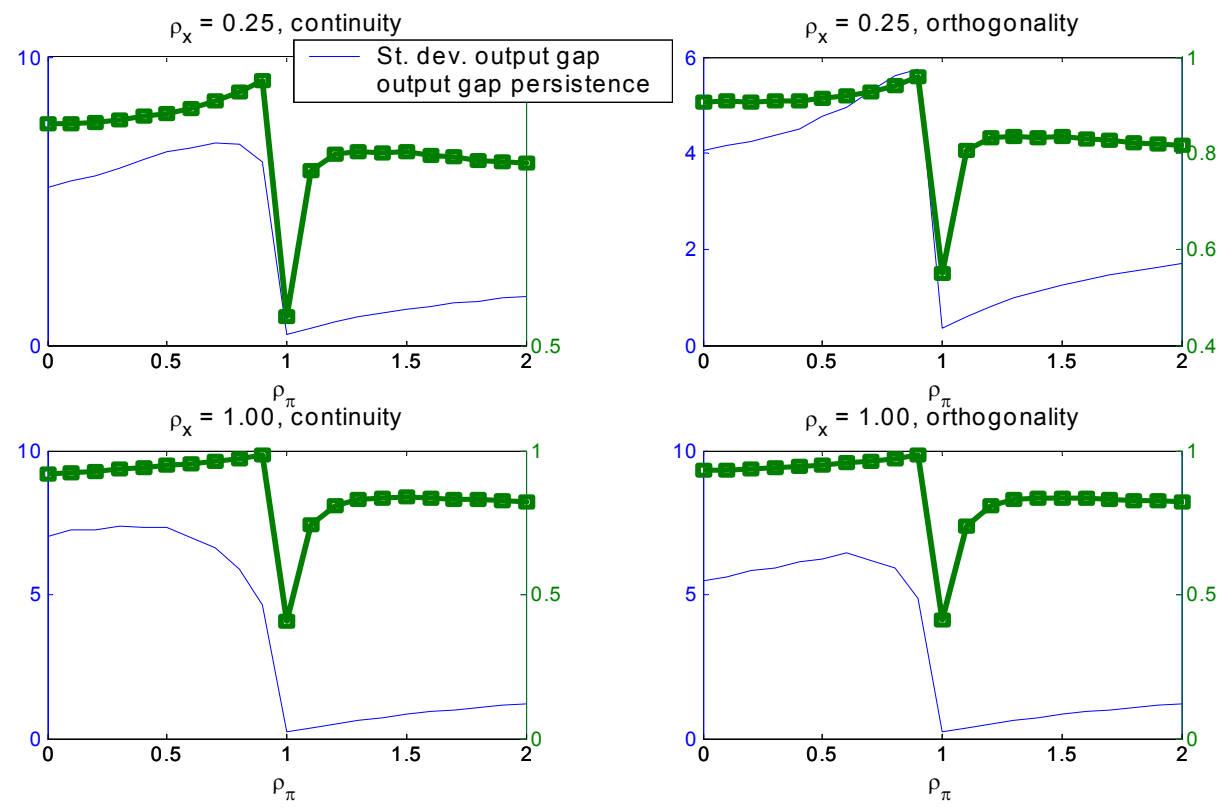

Figure 2: Figure 17. Robustness check with forward looking Taylor rule.
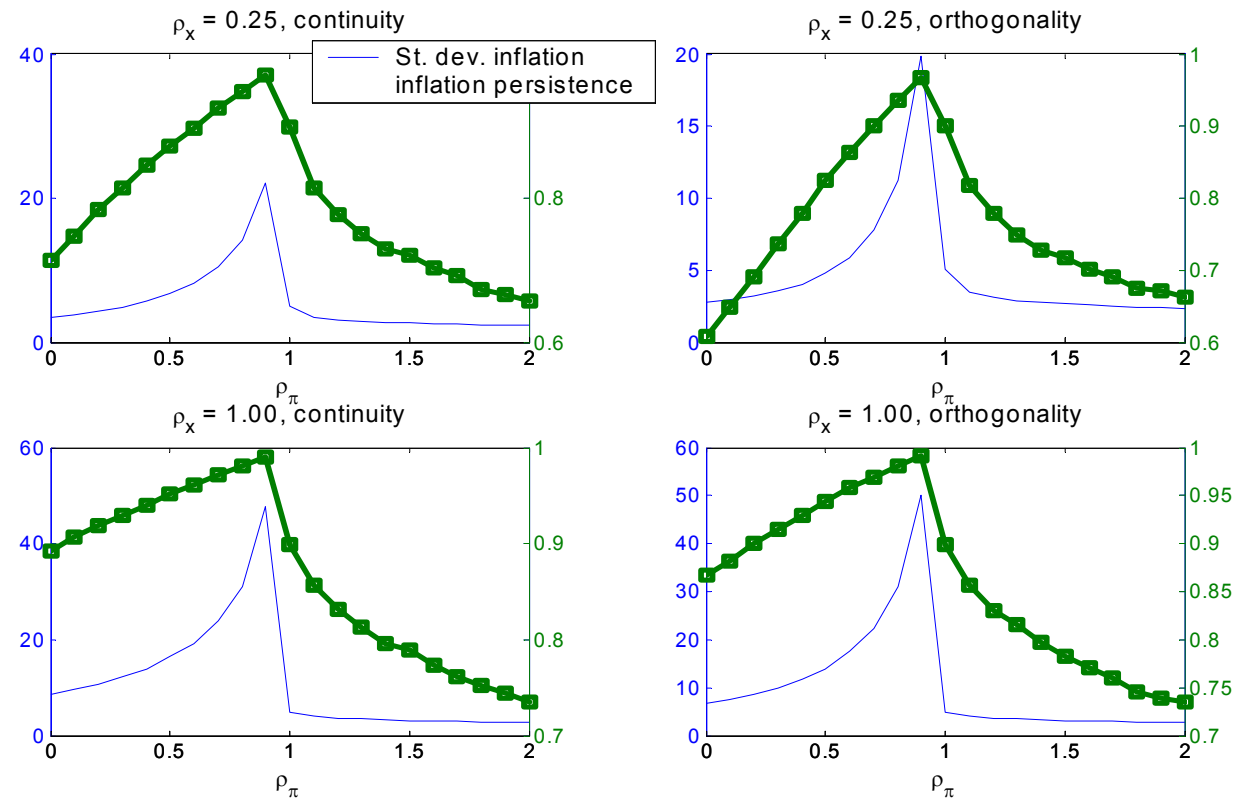

Figure 16. Robustness check with forward looking Taylor rule. 

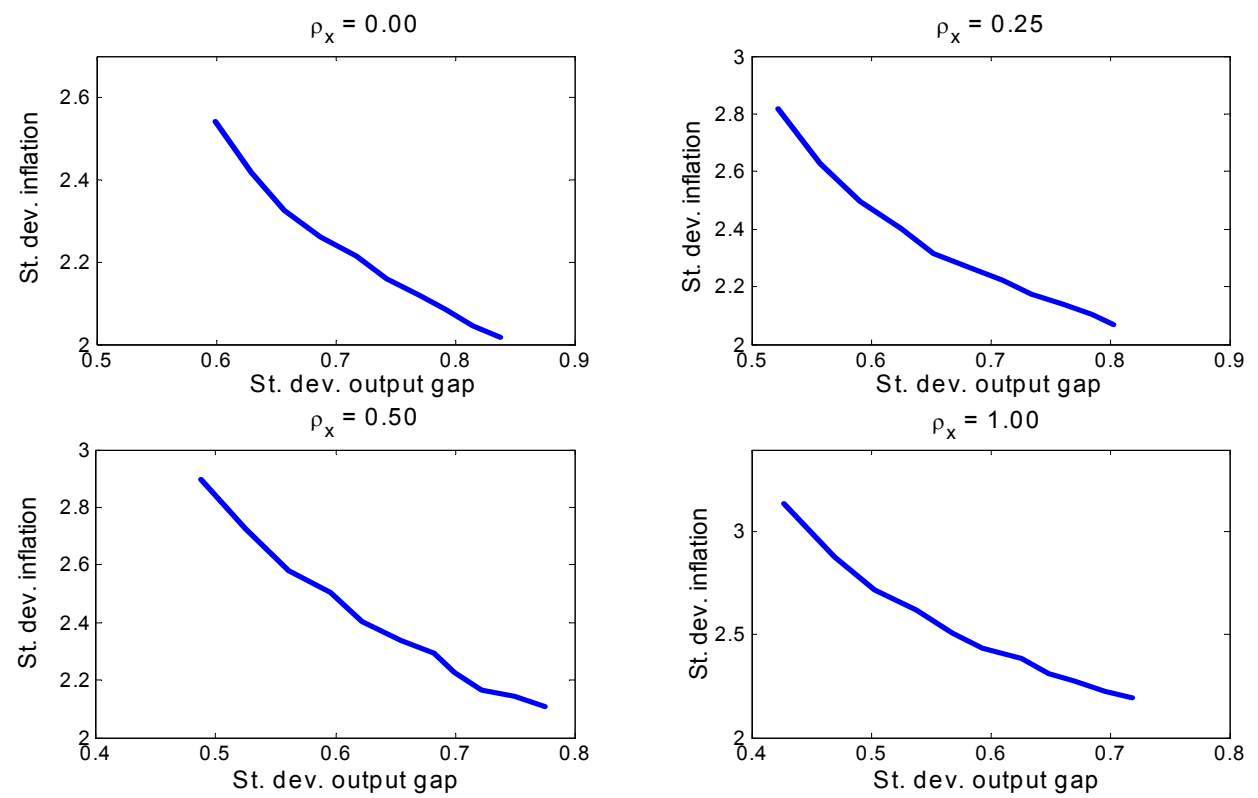

Figure 18. Robustness check with high relative risk aversion. $[\sigma=5]$
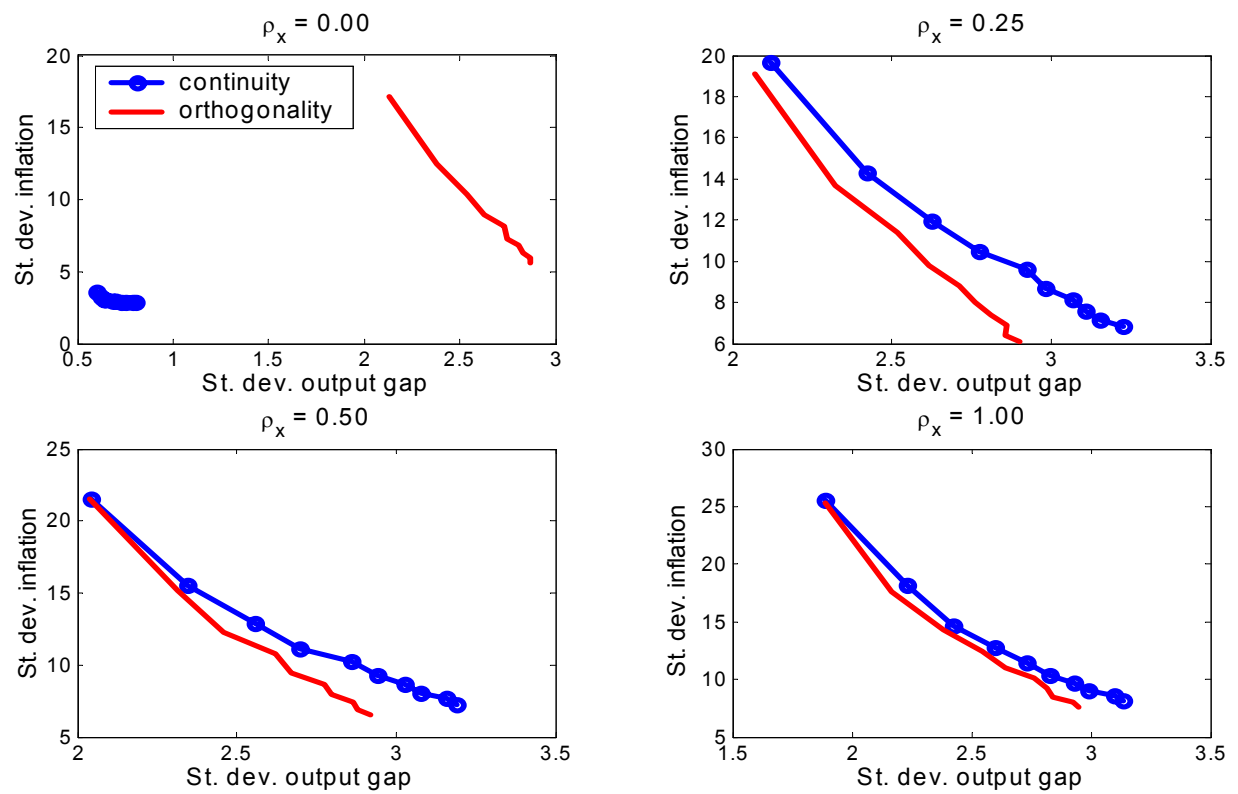

Figure 19. Robustness check with high relative risk aversion. $[\sigma=5]$ 

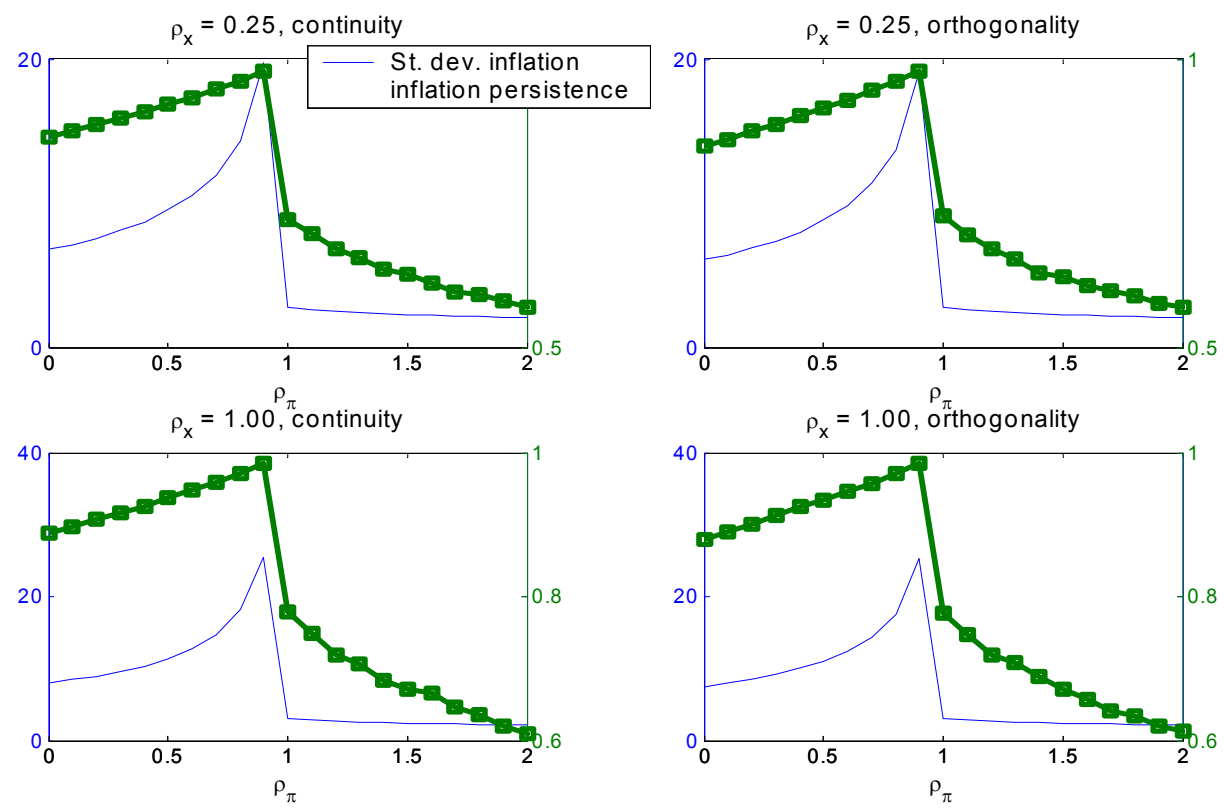

Figure 20. Robustness check with high relative risk aversion. $[\sigma=5]$
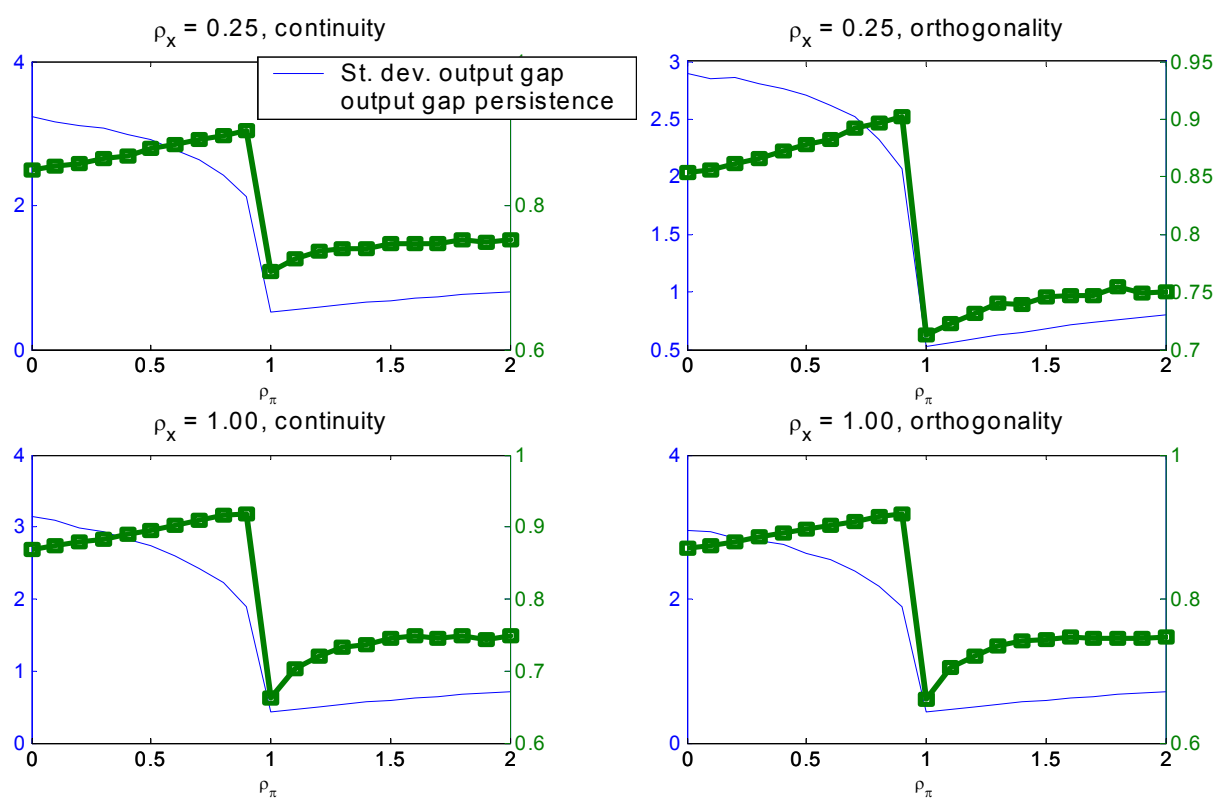

Figure 21. Robustness check with high relative risk aversion. $[\sigma=5]$ 

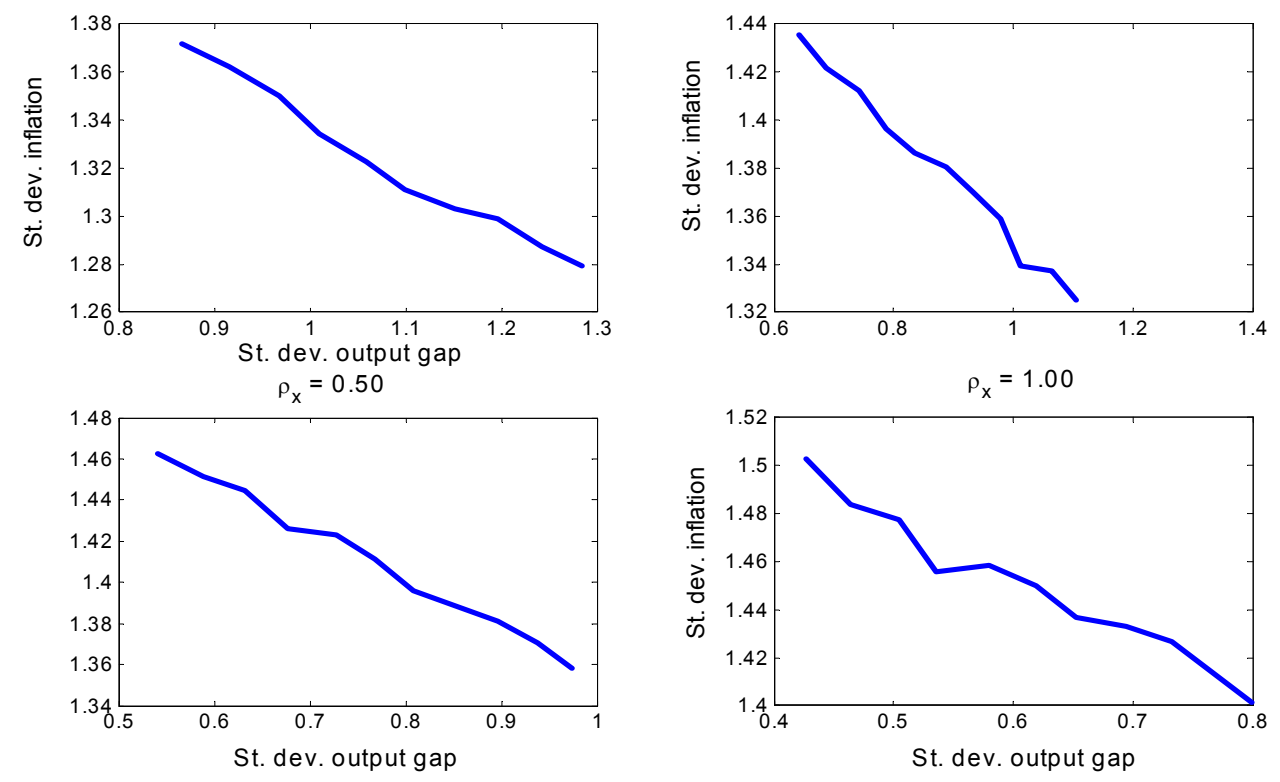

Figure 22. Robustness check with a lower degree of automatic price adjustment. $[w=0.3]$
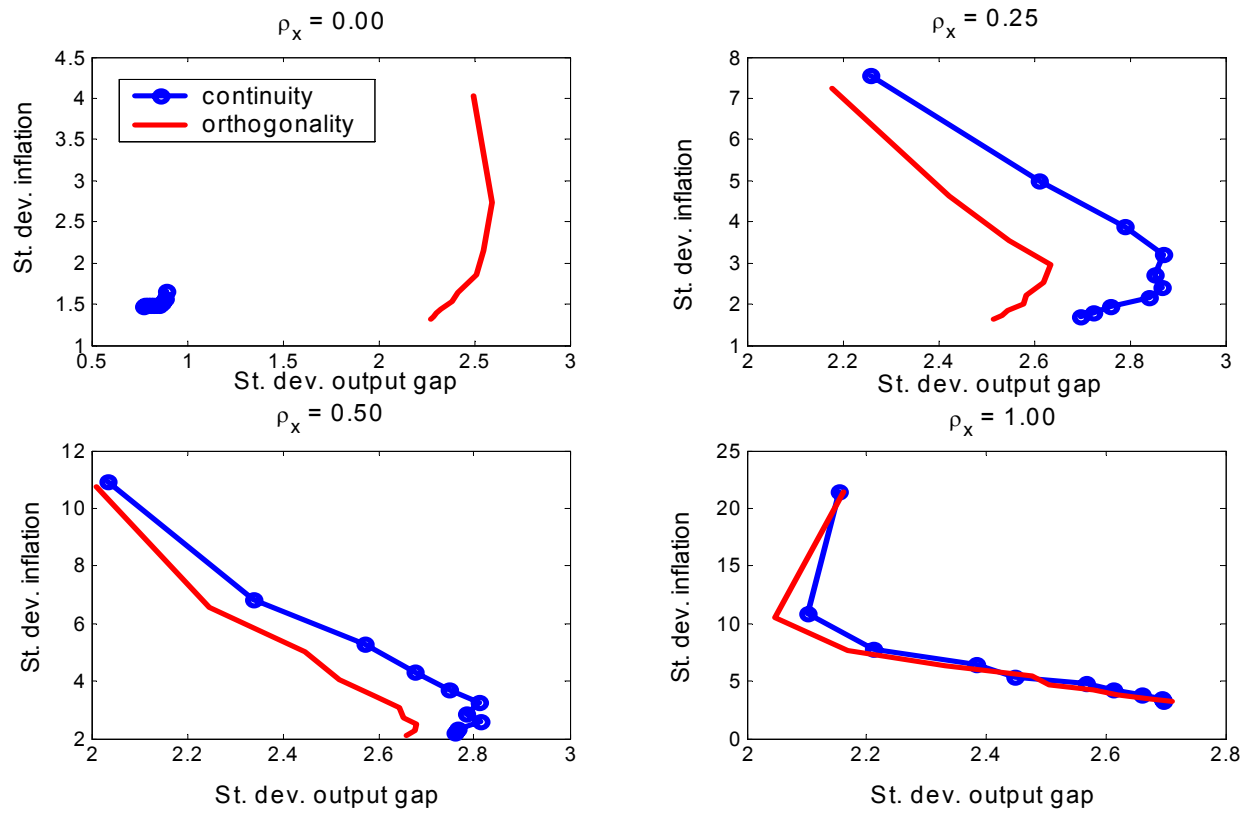

Figure 23. Robustness check with a lower degree of automatic price adjustment.

$$
[w=0.3]
$$



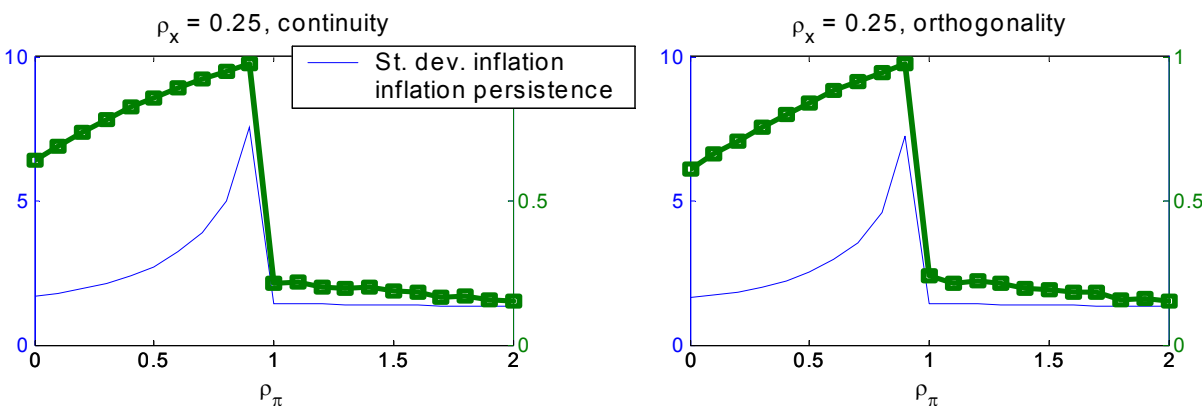

$\rho_{x}=1.00$, continuity

$\rho_{x}=1.00$, orthogonality
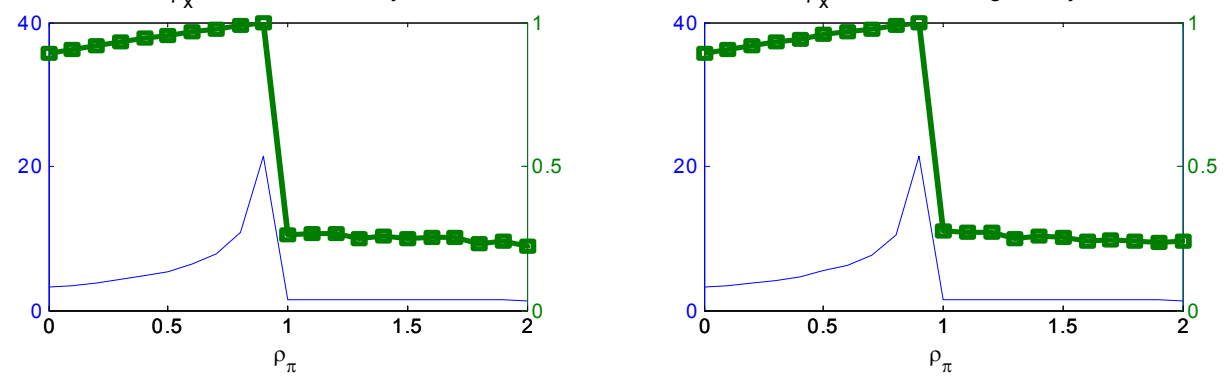

Figure 24. Robustness check with a lower degree of automatic price adjustment.

$$
[w=0.3]
$$
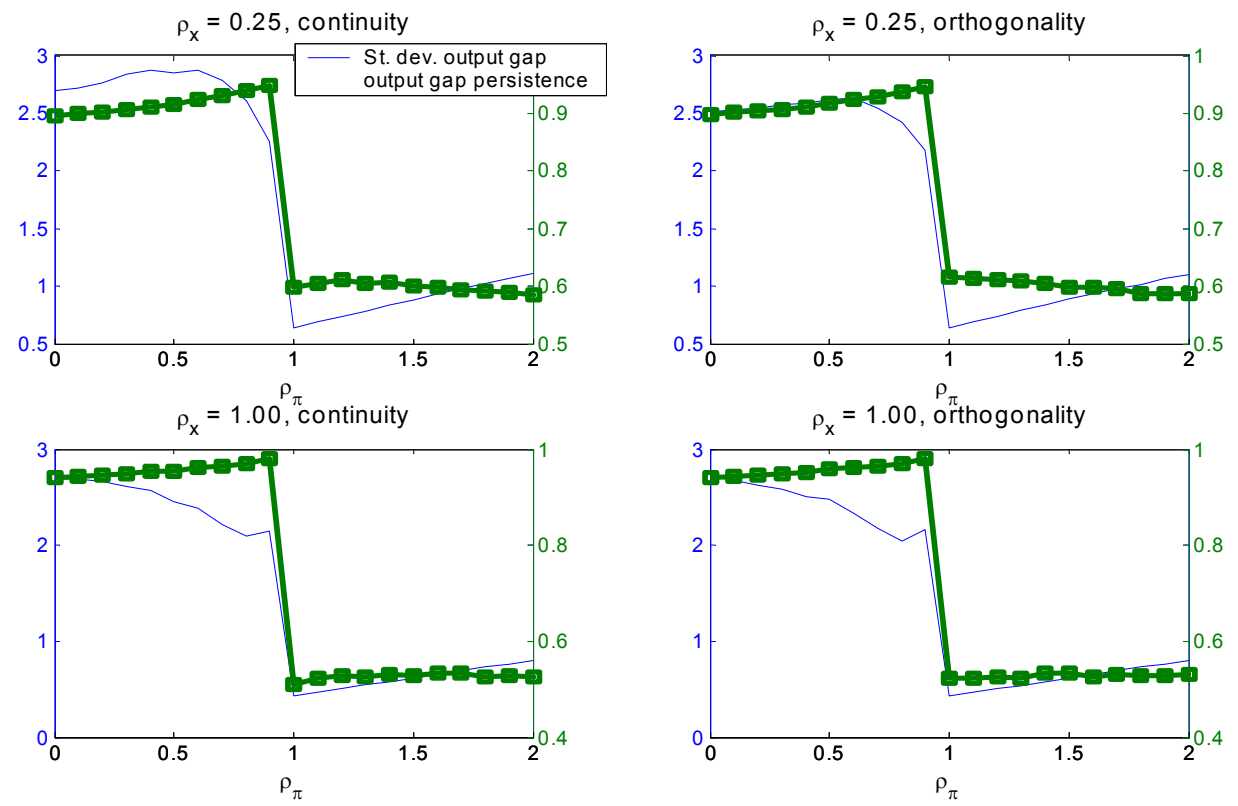

Figure 25. Robustness check with a lower degree of automatic price adjustment. $[w=0.3]$ 